\title{
MicroRNA-150 Inhibits the Activation of Cardiac Fibroblasts by Regulating c-Myb
}

\author{
Peng Deng ${ }^{a}$ Ling Chen ${ }^{b}$ Zheng Liu ${ }^{c}$ Ping Ye ${ }^{d}$ Sihua Wange Jie Wu ${ }^{a}$ Yufeng Yao ${ }^{f}$ \\ Yuan Sun ${ }^{\mathrm{a}}$ Xiaofan Huang ${ }^{\mathrm{a}}$ Linyun Ren ${ }^{\mathrm{a}}$ Anchen Zhang ${ }^{\mathrm{a}}$ Ke Wang $^{\mathrm{a}}$ \\ Chuangyan Wua Zhang Yue ${ }^{a}$ Xuezeng Xud Manhua Chen ${ }^{b}$ \\ aDepartment of Cardiovascular Surgery, Union Hospital, Tongji Medical College, Huazhong University \\ of Science and Technology, Wuhan, ${ }^{b}$ Department of Cardiovascular Medicine, Central Hospital of \\ Wuhan, Wuhan, 'Department of Thoracic Surgery, West China Hospital, Sichuan University, Chengdu, \\ 'Department of Cardiovascular Surgery, Xijing Hospital, Fourth Military Medical University, Xi'an, \\ eDepartment of Thoracic Surgery, Union Hospital, Tongji Medical College, Huazhong University of \\ Science and Technology, Wuhan, ${ }^{\mathrm{f} K e y ~ L a b o r a t o r y ~ o f ~ M o l e c u l a r ~ B i o p h y s i c s ~ o f ~ t h e ~ M i n i s t r y ~ o f ~ E d u c a t i o n, ~}$ \\ College of Life Science and Technology, Center for Human Genome Research, Cardio-X Institute, \\ Huazhong University of Science and Technology, Wuhan, China
}

\section{Key Words}

MiR-150 • Cardiac fibrosis • Cardiac fibroblast • Myofibroblast • c-Myb

\begin{abstract}
Background/Aims: Cardiac fibrosis is the primary cause of deteriorated cardiac function in various cardiovascular diseases. Numerous studies have demonstrated that microRNAs (miRNAs) are critical regulators of myocardial fibrosis. Specifically, many studies have reported that miR-150 is downregulated in cardiovascular diseases, such as acute myocardial infarction (AMI), myocardial hypertrophy and myocardial fibrosis. However, the exact role of miR-150 in these pathological processes remains unknown. Methods: We used the transverse aortic constriction (TAC) mouse model to study the role of miR-150 in cardiac fibrosis induced by pressure overload. After the TAC operation, qRT-PCR was used to measure the expression profiles of miR-150 in left ventricle tissues and populations of primary heart cell types. Then, we used both miR-150 knockout mice and wild type (WT) mice in the TAC model. Changes in cardiac function and pathology were measured using transthoracic echocardiography and pathological analysis, respectively. Furthermore, we predicted the target of miR-150 in cardiac fibroblasts (CFs) and completed in vitro CF transfection experiments using miR-150 analogs and siRNA corresponding to the predicted target. Results: We observed decreased expression levels of miR-150 in hearts suffering pressure overload, and these levels decreased more sharply in CFs than in cardiomyocytes. In addition, the degrees of cardiac function deterioration and cardiac fibrosis in miR-150-/- mice were more severe than were those in WT mice. By transfecting CFs with an miR-150 analog in vitro, we observed that miR-150 inhibited cardiac fibroblast activation. We predicted that the transcription factor c-Myb was the target

P. Deng, L. Chen and Z. Liu contributed equally to this work.

Manhua Chen and Xuezeng Xu Department of Cardiovascular Medicine, Central Hospital of Wuhan, Shengli Street 26, Wuhan 430014, (China); Department of Cardiovascular Surgery, Xijing Hospital, Fourth Military Medical University, West Changle Road 15, Xi'an 710032, (China)




\section{Cellular Physiology Cell Physiol Biochem 2016;38:2103-2122 \\ \begin{tabular}{ll|l} 
DOI: 10.1159/000445568 & $\begin{array}{l}\text { @ } 2016 \text { The Author(s). Published by S. Karger AG, Basel } \\
\text { www.karger.com/cpb }\end{array}$ \\
\cline { 2 - 4 }
\end{tabular} \\ Deng et al.: MicroR-150 Inhibits the Activation of Cardiac Fibroblasts by Regulating c-Myb}

of miR-150 in CFs. Transfecting CFs with c-Myb siRNA eliminated the effects of an miR-150 inhibitor, which promoted CF activation. Conclusion: These findings reveal that miR-150 acts as a pivotal regulator of pressure overload-induced cardiac fibrosis by regulating c-Myb.

(C) 2016 The Author(s)

Published by S. Karger AG, Basel

\section{Introduction}

In the normal adult heart, cardiomyocytes and cardiac fibroblasts (CFs) compose 30$40 \%$ and $60-70 \%$ of the total number of heart cells, respectively [1]. Under normal conditions, CFs exist in a quiescent state and are enmeshed into the interstitium and around blood vessels [2]. CFs have various functions and contribute to the maintenance of the physiological characteristics of the heart. They maintain ECM homeostasis, which is important because the ECM provides a framework for all types of cardiac cells and distributes mechanical tension throughout the cardiac tissue [2]. CFs are also pivotal for cardiac mechanoelectrical transduction; CFs form insulating layers that separate the cardiac conduction system and cardiomyocytes to ensure the proper sequencing of myocardial contractions [3]. Meanwhile, CFs participate in inflammation, angiogenesis and vascular homeostasis by secreting various cytokines $[4,5]$. These cells can also affect cardiomyocyte function via direct or indirect cell-cell interactions [3]. CFs are even more crucial in cardiac pathology. Quiescent CFs act as sentries for the heart because they have the potential to become activated and repair cardiac injury; these cells can perceive myocardial injury and initiate the inflammatory and repair responses. Because cardiomyocytes have a negligible regenerative capacity, the loss of many cardiomyocytes induced by sudden myocardial damage is repaired by CFs, which remove dead cells as well as synthesize and assemble ECM into collagen-based scar tissue that reinforces the damaged area [6]. However, excessive repair may cause the massive accumulation of ECM and eventually result in myocardial fibrosis. Most cardiac diseases are related to fibrosis that is induced by excessive cardiac tissue repair. Excessive fibrosis results in increased mechanical stiffness and diastolic dysfunction, both of which significantly affect heart function [7]. Furthermore, excessive ECM deposition among cardiomyocytes may destroy their electric coupling, resulting in damaged cardiac contraction [3]. In addition, fibrosis adjacent to the vasculature may affect the exchange of oxygen and nutrients and thereby aggravate the pathological fibrosis response [8]. Therefore, methods of mitigating myocardial fibroblast action could serve as important strategies for the treatment of myocardial fibrosis.

MicroRNAs (miRNAs) are endogenous, single-stranded, noncoding RNAs that are approximately 20 nucleotides long and highly conserved. MiRNAs regulate the expression of target genes at the posttranscriptional level by binding to the 3'UTRs of target mRNAs and promoting their degradation or translational repression [9]. Each miRNA can regulate from dozens to hundreds of target mRNAs [10]. MiRNAs are key regulators of almost all cellular processes, including proliferation, differentiation, aging, death, and stem cell self-renewal maintenance $[11,12]$. A growing body of evidence suggests that miRNAs are modulators of the cardiovascular system and participate in virtually all aspects of cardiovascular physiology and pathology, including cardiovascular development, atherosclerosis, arrhythmias, myocardial infarction, hypertrophy, cardiac fibrosis and heart failure [13-16]. Transgenic animal models of intracellular miRNA overexpression or knockout have demonstrated that miRNAs are key regulators of stress-triggered cardiac remodeling [17]. Several recent studies performed microarray analyses of miRNAs in hypertrophic and failing hearts and revealed signature patterns of miRNAs that are abnormally expressed during pathological conditions. Unique miRNA expression signatures may act as diagnostic tools or therapeutic targets for cardiovascular disease $[18,19]$.

Many previous studies have reported that miR-150 was downregulated in heart tissue after cardiac injury, including acute myocardial infarction, myocardial hypertrophy, cardiac fibrosis and heart failure [20-22]. In our previous studies, we found that plasma miR-150 level was positively associated with atrial fibrillation severity [23]. We also observed that 


\section{Cellular Physiology \\ Cell Physiol Biochem 2016;38:2103-2122 and Biochemistry

miR-150 regulates the migration of monocytes to the area of myocardial infarction by targeting CXCR4, thereby reducing the occurrence and development of myocardial fibrosis and protecting heart function [24]. These results suggest that miR-150 in peripheral blood can regulate the occurrence and development of cardiac fibrosis. However, the exact role of miR-150 in these pathological processes remains unknown.

In the present study, we analyzed the miR-150 expression levels in the pressureoverloaded hearts of mice and identified that miR-150 expression was decreased compared with that of the controls, and the lowest level was approximately $66 \%$ lower than the normal expression level. Simultaneously, we assessed miR-150 expression in primary heart cell populations after transverse aortic constriction (TAC) and observed that miR-150 expression levels decreased more sharply in CFs than in other cells. Thus, we sought to determine whether in situ miR-150 expression in cardiac tissue is involved in cardiac fibrosis. The aim of this research was to explore the role of miR-150 in local cardiac tissue during cardiac remodeling and provide a theoretical basis for clinical diagnoses and treatments.

\section{Materials and Methods}

\section{Animals}

C57BL/6 mice were purchased from Beijing Huafukang Biotechnology Co., Ltd (Beijing, China). The miR-150-/- mice were bred in a C57BL/6 background and were purchased from the Jackson Laboratory. The mice were bred under standard vivarium conditions (temperature, $21 \pm 1^{\circ} \mathrm{C}$; humidity, $55-60 \%$ ) and were provided sterile food and water. All animal studies were approved by the Animal Care and Utilization Committee of Huazhong University of Science and Technology and were in accordance with the Institutional Animal Care and Use Committee of Tongji Medical College, Huazhong University of Science and Technology.

\section{TAC mouse models}

MiR-150-/- and C57BL/6 mice (8 to 10 weeks old) were anesthetized with pentobarbital sodium (75 $\mathrm{mg} / \mathrm{kg}$, intraperitoneally [i.p.]). Then, a 24-G trocar was intubated into the mouse trachea and connected to artificial respiration. A median thoracotomy was performed halfway through the upper sternum, and the thymic lobes were separated to expose part of the aortic arch and branches. A thread was then carefully placed around the region of the aortic arch between the first and second branches. A 27-G syringe needle was placed parallel with the separated aortic arch, the thread was tightly ligatured, and then the syringe needle was carefully removed. Finally, the surgical incision was closed, and the breathing machine was disconnected. After the surgery, the mice were bred under standard vivarium conditions.

\section{CF isolation and culture}

Primary CFs were isolated from male C57BL/6 or miR-150-/- mice (6 to 8 weeks old). The mice were anesthetized with pentobarbital sodium $(75 \mathrm{mg} / \mathrm{kg}$, i.p.). Then, the hearts were removed and quickly dissected. The heart samples were washed in $4^{\circ} \mathrm{C}$ phosphate-buffered saline (PBS) to remove blood and impurities, the samples were then digested with pancreatic enzyme (Sigma, T1426) for 8 minutes and collagenase type II (Sigma, C6885) for 30 to 60 minutes at $37^{\circ} \mathrm{C}$. Then, the heart cells were washed in $4^{\circ} \mathrm{C}$ PBS and centrifuged for 8 minutes at $250 \mathrm{~g}$. Liquid supernatant was removed, and the cells were washed two more times. The cells were cultured in DMEM (Gibco) containing 10\% fetal bovine serum (FBS) (Gibco) and penicillin-streptomycin ( $100 \mathrm{U} / \mathrm{ml}$ penicillin, $100 \mathrm{~g} / \mathrm{ml}$ streptomycin) (Gibco) at $37^{\circ} \mathrm{C}$ with $5 \% \mathrm{CO}_{2}$. After 2 hours, the CFs had attached onto the culture plates, and the suspended cells were then removed. The media was replaced with fresh media to continue the culture. The cells were subcultured when they reached $90 \%$ confluency. Cells from passages 3 to 6 were used in subsequent experiments.

Cell transfection (miR-150-5p)

The constructs of the synthetic miR-150 analogs are provided below.

Has-miR-150-5p:

mimic: 5'-UCUCCCAACCCUUGUACCAGUG-3',

3'-CUGGUACAAGGGUUGGGAGAUU-5'; 


\title{
Cellular Physiology Cell Physiol Biochem 2016;38:2103-2122 \\ \begin{tabular}{ll|l} 
DOI: 10.1159/000445568 & $\begin{array}{l}\text { @ } 2016 \text { The Author(s). Published by S. Karger AG, Basel } \\
\text { www.karger.com/cpb }\end{array}$ \\
\cline { 2 - 3 } & Published online: May 17, 2016 & Diochemistry
\end{tabular} \\ Deng et al.: MicroR-150 Inhibits the Activation of Cardiac Fibroblasts by Regulating c-Myb
}

\author{
mimic-NC: 5'-UUCUCCGAACGUGUCACGUTT-3', \\ 3'-ACGUGACACGUUCGGAGAATT-5'; \\ inhibitor: 5'-CACUGGUACAAGGGUUGGGAGA-3'; \\ inhibitor-NC: 5'-UUGUACUACACAAAAGUACUG-3',
}

Analogs (mimic $5 \mathrm{nM}$ and inhibitor $10 \mathrm{nM}$ ) and Lipofectamine 2000 (Invitrogen) were mixed in 200 $\mu \mathrm{l}$ of serum-free media for 20 minutes at room temperature to form transfection complexes. Then, the cells were incubated with the transfection complexes in Opti-MEM media (Gibco) for 4 to 6 hours, which was subsequently replaced with fresh DMEM containing 10\% FBS to continue the culture. The transfection efficiencies of the analogs were measured using fluorescence and were $\geq 75 \%$. Proliferation, migration and mRNA assays were performed after 48 hours, and proteomic analysis was performed after 72 hours.

Silencing endogenous expression of c-Myb

Small interfering RNA (siRNA) duplexes targeting c-Myb were used to silence the endogenous expression of c-Myb. We obtained three types of synthesized siRNAs from Shanghai GenePharma Co., Ltd. The sequences of these siRNAs are listed below. The control siRNA was also obtained from Shanghai GenePharma Co., Ltd. The c-Myb siRNA and control siRNA (50 nM) were transfected into CFs using Lipofectamine 2000 (Invitrogen). The transfection efficiencies of the siRNAs into the CFs were $\geq 75 \%$.

SiRNA (c-Myb):

1. Myb-Mus-662: 5'- GGUGGCACAACCAUUUGAATT-3'

2. Myb-Mus-1403: 5'-GCACCAUUCUGGACAAUGUTT-3'

3. Myb-Mus-1977: 5'-GACACCUGUAUCAGAAGAUTT-3'

CF proliferation assay

CF proliferation was assayed using a Cell Counting Kit-8 (CCK-8) (Dojindo, Shanghai, China). In brief, CFs were plated in 96-well plates at a density of 2000 to 10,000 cells per well. Then, the cells were transfected with the miR-150 analogs as described above, and CF proliferation was assayed after 48 hours. Before the assay, the cells were serum-starved in serum-free media for 12 to 24 hours. Then, the media in each well was replaced with a mixture of fresh serum-free DMEM $(90 \mu \mathrm{l})$ and CCK-8 reagent $(10 \mu \mathrm{l})$, and the cells were cultured in an RS Biotech incubator. The assay was performed after 4 to 6 hours of incubation.

\section{CF migration assay}

CF migration was measured using a scratch assay. The CFs were plated in 6-well plates and transfected with miR-150 mimic, inhibitor, scrambled miRNA-NC, or siRNA, with or without $10 \mathrm{ng} / \mathrm{mL}$ TGF- $\beta$. After 48 hours, a linear wound across the $\mathrm{CF}$ monolayer in the plates was made with a $1 \mathrm{~mL}$ micropipette tip. Then, the cells were washed with PBS to remove debris and were cultured in fresh DMEM containing 10\% FBS. TGF- $\beta$ was added to the wells according to the different treatments. The sizes of the wounds were then measured at the indicated time points.

\section{Western blot}

Total protein was extracted from the cells, mixed with $5 \times$ loading buffer and heated at $96^{\circ} \mathrm{C}$ for 10 minutes. The proteins were stored at $-20^{\circ} \mathrm{C}$. A $6 \%$ spacer gel and a $10 \%$ separation gel were used. After being electrophoretically separated, the proteins were transferred onto $0.45-\mu \mathrm{m}$ PVDF membranes. Then, the membranes were blocked with 5\% fat-free milk powder in TBS-Tween (TBST) for 1 hour at room temperature and were then incubated with primary antibodies [anti-collagen I antibody, America, Abcam, ab34710; anti-alpha-smooth muscle actin ( $\alpha$-SMA), America, Abcam, ab32575; anti-GAPDH, America, Abcam, ab70700; anti-c-Myb, America, Santa Cruz, SC-7874] overnight at $4^{\circ} \mathrm{C}$. All antibodies were diluted 1:2000 in 5\% BSA. The membranes were washed 3 times with TBST for 8 minutes each and were then incubated for 1 hour in secondary horseradish peroxidase (HRP)-conjugated antibodies (goat anti-rabbit IgG H\&L, America, Abcam, ab81053) diluted 1:2000 in 5\% BSA. The protein blots were visualized by chemiluminescence (KPL, USA). The results were analyzed using ImageJ software (ImageJ v1.48).

Quantitative reverse transcription-polymerase chain reaction ( $q R T-P C R$ )

Total RNA was extracted from cultured CFs and cardiac tissues using TRIzol reagent (Invitrogen, 15596-018) according to the manufacturer's protocol. Total RNA $(0.2 \mu \mathrm{g})$ was reverse transcribed to 


\section{Cellular Physiology Cell Physiol Biochem 2016;38:2103-2122 \\ \begin{tabular}{c|l} 
DOI: 10.1159/000445568 & $\begin{array}{l}\text { @ } 2016 \text { The Author(s). Published by S. Karger AG, Basel } \\
\text { www.karger.com/cpb }\end{array}$ \\
\cline { 2 - 3 }
\end{tabular}}

obtain cDNA using a High Capacity cDNA Reverse Transcription Kit (Invitrogen, 4368813) according to the manufacturer's protocol. The RNA levels of $\alpha$-SMA, c-Myb, and collagen I-a1 were measured using the SYBR Green I incorporation method; GAPDH was used as an internal control. The miR-150 levels were measured using a TaqMan MicroRNA Assay Kit (TaqMan miR-150 MicroRNA Assay Kit, Applied Biosystems) according to the manufacturer's protocol; U6 was used as an internal control.

The primer sequences are provided below:

GAPDH: Forward: 5'-TGA CCA CAG TCC ATG CCATC-3'

Reverse: 5'-GAC GGA CAC ATT GGG GGTAG-3'

- -SMA: Forward: 5'-GTC CCA GAC ATC AGG GAG TAA-3'

Reverse: 5'-TCG GAT ACT TCA GCG TCA GGA-3'

c-Myb: Forward: 5'-GCA GGC ATT ACC AAC ACAGA-3'

Reverse: 5'-TCT CCC AAA CAG GAA ACAGG-3'

Collagen I: Forward: 5'-CAT CGT GGC TTC TCT GGTCT-3'

Reverse: 5'-CCG TTG AGT CCG TCT TTGC-3'

Immunofluorescence

CFs were cultured in a 24-well plate and treated. After 96 hours, the cells were fixed in 4\% paraformaldehyde for 10 minutes at room temperature and were washed 3 times in PBS for 5 minutes each. Then, the cells were permeabilized in $0.2 \%$ Triton X-100 for 10 minutes at room temperature and were washed 3 times in PBS for 5 minutes each. The cells were blocked with 5\% BSA for 1 hour at room temperature and were incubated with primary antibodies (anti- $\alpha$-SMA, America, Abcam, ab32575; antivimentin, America, Abcam, ab11256) overnight at $4^{\circ} \mathrm{C}$. Next, the cells were washed 3 times in PBS for 5 minutes each and were incubated with secondary antibodies for 1 hour at room temperature. All antibodies were diluted 1:200 in 2\% BSA. The cells were then washed 3 times in PBS for 5 minutes each. Nuclei were stained using $0.01 \%$ DAPI for 1 minute. Finally, the cells were washed, and the fluorescence was measured. The numbers of $\alpha$-SMA+ cells (red) and vimentin + cells (green) in five randomly selected fields per section were determined using fluorescence microscopy.

Immunohistochemistry

Paraffin sections of cardiac tissues were dewaxed in water, and antigen retrieval was performed in a pressure cooker. Then, the sections were blocked with 5\% BSA for 1 hour at room temperature and were incubated with primary antibodies (anti- $\alpha$-SMA, America, Abcam, ab32575; anti-CD68, America, Abcam, ab76308) overnight at $4^{\circ} \mathrm{C}$. Next, the sections were washed with PBS 3 times for 5 minutes each and were incubated with secondary antibodies for 1 hour at room temperature. All antibodies were diluted 1:200 in 2\% BSA. The slides were then washed with PBS 3 times for 5 minutes each, and color development was performed using DAB. Finally, the sections were washed, and the results were obtained using optical microscopy. The numbers of $\alpha$-SMA+ cells and CD68+ cells in five randomly selected fields per section were determined.

Transthoracic echocardiography and hemodynamic analysis of cardiac function

Mouse cardiac function was measured using a Vevo 2100 high-resolution micro-imaging system with a 30-MHz transducer (VisualSonics, Toronto, Ontario, Canada), as described previously [24]. In brief, the mice were anesthetized with $0.5 \%$ pentobarbital sodium $(75 \mathrm{mg} / \mathrm{kg}$, i.p.). Then, the mid-ventricular short axis and parasternal long axis were imaged using M-model echocardiography. The left ventricular ejection fraction (EF) and fractional shortening (FS) were assessed from the digital images, using the root of the ventricular papillary muscle as the baseline as well as the methods described previously [24]. Echocardiographic acquisition and analysis were performed by a technician who was blinded to the treatment groups. $\mathrm{EF}=(\mathrm{LV}$ Vold-LV Vols)/LV Vold*100\%; FS=(LVIDd-LVIDs)/LVIDd*100\%; CO=(LV Vold-LV Vols)*HR.

Separation of cardiomyocytes and cardiac fibroblasts from mouse hearts

Adult mouse cardiomyocytes and CFs were isolated in two steps. First, cardiomyocytes were isolated as described previously [25]. Second, CFs were isolated using the differential adhesion method [26]. In brief, a heart was perfused and digested using collagenase II. Then, the dissociated cardiomyocytes and noncardiomyocytes were sedimented by gravity. The bottom layer, which was enriched with cardiomyocytes, was collected. The supernatant layer, which contained non-cardiomyocytes, including CFs, smooth muscle 


\section{Cellular Physiology \\ Cell Physiol Biochem 2016;38:2103-2122 \\ \begin{tabular}{l|l}
\hline DOI: $10.1159 / 000445568$ & O 2016 The Author(s). Published by S. Karger AG, Basel
\end{tabular} and Biochemistry Published online: May 17, 2016 www.karger.com/cpb \\ Deng et al.: MicroR-150 Inhibits the Activation of Cardiac Fibroblasts by Regulating c-Myb}

cells, endothelial cells and pericytes, was also collected. The non-cardiomyocytes were then cultured in 6-well plates in DMEM containing 10\% FBS. After 2 hours, the only attached cells were CFs, which were then collected and cultured in new 6-well plates in DMEM containing 10\% FBS.

\section{Data analysis}

All data are expressed as the mean \pm SEM and were analyzed statistically using one-way ANOVA followed by the least significant difference t-test (LSD t-test) and Dunnett's t-test (SPSS 17.0). All data were tested for normality and homogeneity of variance before comparisons between groups were performed. The differences were considered statistically significant at values of $\mathrm{p}<0.05$. All experiments were repeated three times.

\section{Results}

Expression profiles of miR-150 in mouse hearts after TAC

To investigate the role of miR-150 in pressure overload-induced cardiac fibrosis, we measured the expression profiles of miR-150 in the left ventricles of TAC hearts at $0,1,2,4$, 8 , and 12 weeks using qRT-PCR. We observed that miR-150 expression levels were reduced significantly in the cardiac tissues of mice in the TAC models. The miR-150 expression levels in the heart tissues decreased gradually in the early stages post-operation. The lowest expression level was reached between 2 to 4 weeks post-operation and was approximately two-thirds lower than the normal level. In the later stage, the expression levels began to recover gradually but remained below the normal level (Fig. 1A).

MiR-150 expression levels decreased more significantly in CFs than in cardiomyocytes after TAC

To discover the primary cells in which miR-150 expression changed in pressureoverloaded hearts, we separated the cardiomyocytes and CFs from the hearts of TAC mice at 0 , $1,2,4,8$, and 12 weeks post-operation. The purities of the separated cardiomyocytes and CFs were $\geq 85 \%$ and $\geq 80$, respectively (data not shown). We examined the miR-150 expression patterns in these cells using qRT-PCR. We observed that the miR-150 expression levels in CFs were higher than those in myocardial cells and were remarkably downregulated, with a decrease of nearly 2.5 -fold at 2 and 4 weeks post-operation. The fluctuation range of the miR-150 expression levels in CFs was significantly larger than that in cardiomyocytes. The miR-150 expression levels in myocardial cells displayed no significant differences among the time points (Fig. 1B).
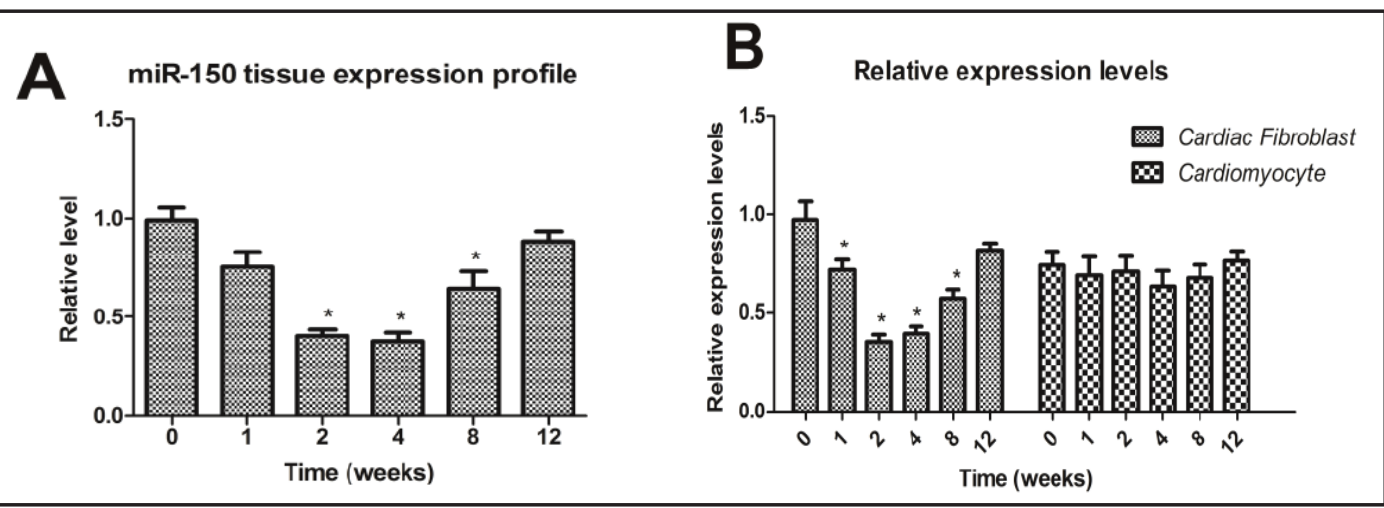

Fig. 1. MiR-150 expression levels in the cardiac tissue and populations of primary heart cell types of WT TAC mice. (A) The expression levels of miR-150 in the left ventricles of TAC mice at $0,1,2,4,8,12$ weeks post-operation were measured using qRT-PCR. (B) The expression levels of miR-150 in cardiomyocytes and CFs of TAC mice at $0,1,2,4,8,12$ weeks post-operation were measured using qRT-PCR. $* \mathrm{p}<0.05$. 


\section{Cellular Physiology Cell Physiol Biochem 2016;38:2103-2122 \begin{tabular}{l|l|l} 
DOI: 10.1159/000445568 & $\begin{array}{l}\text { @ 2016 The Author(s). Published by S. Karger AG, Basel } \\
\text { www.karger.com/cpb }\end{array}$ \\
\hline
\end{tabular}

Table 1. Echocardiographic parameters in anesthetized wild-type and miR-150 KO mice 4 weeks post-TAC, $\left(\mathrm{n}=8-10\right.$ per group). ${ }^{*} \mathrm{p}<0.05$ and ${ }^{* *} \mathrm{p}<0.01$ for TAC(WT) / Sham(WT) or TAC(miR-150-/-) / Sham(miR-150-/-); \# p $<0.05$ and $* * \mathrm{p}<0.01$ for TAC (miR-150-/-) / TAC(WT)

\begin{tabular}{|c|c|c|c|c|}
\hline & & $4 \mathrm{We}$ & & \\
\hline & Shal & & TAC & \\
\hline & WT & miR-150-/- & WT & miR-150-/- \\
\hline HR (bpm) & $421 \pm 14.57$ & $419 \pm 10.31$ & $476 \pm 14.07^{*}$ & $490 \pm 14.31 *$ \\
\hline LVIDs (mm) & $1.73 \pm 0.09$ & $1.7 \pm 0.1$ & $1.51 \pm 0.09 *$ & $1.32 \pm 0.1$ * \# \\
\hline LVIDd (mm) & $2.91 \pm 0.11$ & $2.89 \pm 0.18$ & $2.41 \pm 0.12 *$ & $1.92 \pm 0.18 * * \#$ \\
\hline LV Vols $(\mu \mathrm{l})$ & $7.71 \pm 0.68$ & $7.58 \pm 0.52$ & $4.58 \pm 0.53 * *$ & $2.13 \pm 0.42$ ** \#\# \\
\hline LV Vold $(\mu \mathrm{l})$ & $32.91 \pm 4.68$ & $31.82 \pm 4.62$ & $31.84 \pm 4.18$ & $30.59 \pm 4.27$ \\
\hline $\mathrm{SV}(\mu \mathrm{l})$ & $25.19 \pm 4.68$ & $24.24 \pm 4.62$ & $27.26 \pm 4.63$ & $28.46 \pm 4.66$ \\
\hline $\mathrm{EF}(\%)$ & $76.18 \pm 4.23$ & $75.79 \pm 3.74$ & $85.26 \pm 3.67 *$ & $92.79 \pm 2.34$ ** \# \\
\hline FS (\%) & $40.68 \pm 1.26$ & $41.22 \pm 1.14$ & $37.19 \pm 1.69 *$ & $31.29 \pm 2.84^{* *} \#$ \\
\hline $\mathrm{CO}(\mathrm{ml} / \mathrm{min})$ & $10.63 \pm 2.23$ & $10.15 \pm 1.93$ & $12.98 \pm 2.31 *$ & $13.95 \pm 2.27 * *$ \\
\hline LVPWs (mm) & $1.7 \pm 0.14$ & $1.79 \pm 0.19$ & $1.9 \pm 0.14$ & $2.41 \pm 0.2 * * \#$ \\
\hline LVPWd (mm) & $1.25 \pm 0.12$ & $1.24 \pm 0.13$ & $1.63 \pm 0.17 *$ & $2.13 \pm 0.19$ ** \# \\
\hline
\end{tabular}

Table 2. Echocardiographic parameters in anesthetized wild-type and miR-150 KO mice 8 weeks post-TAC, $\left(\mathrm{n}=8-10\right.$ per group). ${ }^{*} \mathrm{p}<0.05$ and ${ }^{* *} \mathrm{p}<0.01$ for TAC(WT)/Sham(WT) or TAC(miR-150-/-) / Sham(miR-150-/-); \# p $<0.05$ and ** $\mathrm{p}<0.01$ for TAC(miR-150-/-) / TAC(WT)

\begin{tabular}{|c|c|c|c|c|}
\hline \multicolumn{5}{|c|}{8 Weeks } \\
\hline & \multicolumn{2}{|c|}{ Sham } & \multicolumn{2}{|c|}{ TAC } \\
\hline & WT & miR-150-/- & WT & miR-151-/- \\
\hline HR (bpm) & $440 \pm 20.62$ & $435 \pm 30.74$ & $437 \pm 23.67$ & $447 \pm 19.71$ \\
\hline LVIDs (mm) & $1.58 \pm 0.08$ & $1.59 \pm 0.07$ & $1.96 \pm 0.27 *$ & $3.45 \pm 0.13^{* *} \# \#$ \\
\hline LVIDd (mm) & $2.80 \pm 0.11$ & $2.84 \pm 0.1$ & $2.82 \pm 0.39$ & $4.19 \pm 0.2 * * \# \#$ \\
\hline LV Vols $(\mu \mathrm{l})$ & $7.72 \pm 1.66$ & $7.72 \pm 0.81$ & $24.92 \pm 3.49 * *$ & $40.17 \pm 3.65$ ** \#\# \\
\hline LV Vold $(\mu \mathrm{l})$ & $31.06 \pm 2.22$ & $32.25 \pm 3.21$ & $43.69 \pm 3.16^{*}$ & $53.86 \pm 3.45$ ** \# \\
\hline $\mathrm{SV}(\mu \mathrm{l})$ & $23.34 \pm 1.69$ & $24.53 \pm 3.49$ & $18.78 \pm 0.85 *$ & $13.69 \pm 2.22$ ** \#\# \\
\hline EF $(\%)$ & $75.26 \pm 4.52$ & $75.83 \pm 3.93$ & $43.19 \pm 4.14^{* *}$ & $25.44 \pm 3.99$ ** \#\# \\
\hline FS (\%) & $43.6 \pm 0.88$ & $42.9 \pm 1.33$ & $30.37 \pm 3.52 * *$ & $17.46 \pm 1.44$ ** \#\# \\
\hline $\mathrm{CO}(\mathrm{ml} / \mathrm{min})$ & $10.27 \pm 0.81$ & $10.64 \pm 1.37$ & $8.21 \pm 0.59 *$ & $6.15 \pm 1.23 * * \#$ \\
\hline LVPWs (mm) & $1.77 \pm 0.05$ & $1.76 \pm 0.06$ & $1.57 \pm 0.07 *$ & $1.27 \pm 0.05^{* *} \#$ \\
\hline LVPWd (mm) & $1.24 \pm 0.05$ & $1.25 \pm 0.06$ & $1.13 \pm 0.08$ & $0.93 \pm 0.08 * * \#$ \\
\hline
\end{tabular}

MiR-150 knockout further aggravated cardiac dysfunction in TAC mouse models

To explore the role of miR-150 in pressure overload-induced cardiac fibrosis, we generated TAC and sham-operation mouse models using miR-150-/- and WT mice. The cardiac function of mice in the models was examined using transthoracic echocardiography at 4 and 8 weeks post-operation. Throughout the process, we observed that the cardiac function of mice in the TAC groups was poor, but the WT and the miR-150-/-sham-operation mice exhibited normal cardiac function with no significant differences. In addition, the degree and speed of cardiac function deterioration in miR-150-/- TAC mice were significantly worse than were those in WT mice (Table 1 and 2).

In the fourth week, echocardiography showed that cardiac function had remained normal in the mice that had received a sham-operation. At the same time, the mice in the TAC 


\section{Cellular Physiology \\ Cell Physiol Biochem 2016;38:2103-2122

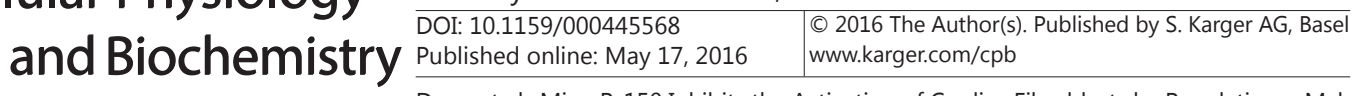 \\ Deng et al.: MicroR-150 Inhibits the Activation of Cardiac Fibroblasts by Regulating c-Myb}

Fig. 2. Mouse cardiac function was measured using transthoracic echocardiography. (A) The cardiac function of sham, WT and miR-150-/mice 4 weeks post-TAC were measured using a Vevo 2100 high-resolution micro-imaging system with a $30-\mathrm{MHz}$ transducer. Statistical results for the EF, FS and CO in sham, WT and miR-150-/- mice ( $\mathrm{n}=8-10)$. (B) The cardiac function of sham, WT and miR-150-/- mice 8 weeks post-TAC. Statistical results for the EF, FS and CO in sham, WT and miR-150-/- mice ( $\mathrm{n}=$ 8-10). ${ }^{*} \mathrm{p}<0.05$ and ${ }^{* *} \mathrm{p}<0.01$ for TAC(WT) / Sham(WT) or TAC(miR-150-/-) / Sham(miR-150-/-); \# $<0.05$ and \#\# $\mathrm{p}<0.01$ for TAC(miR-150-/-) / TAC(WT).

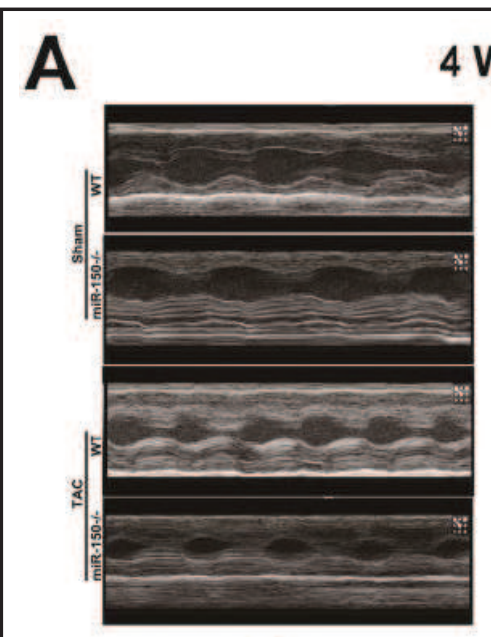

FS

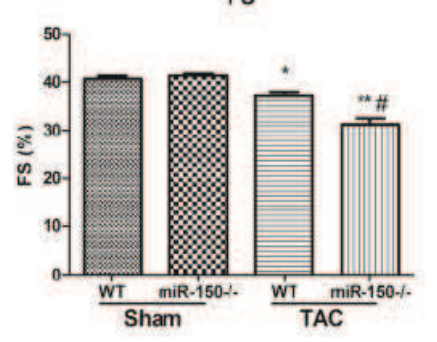

B

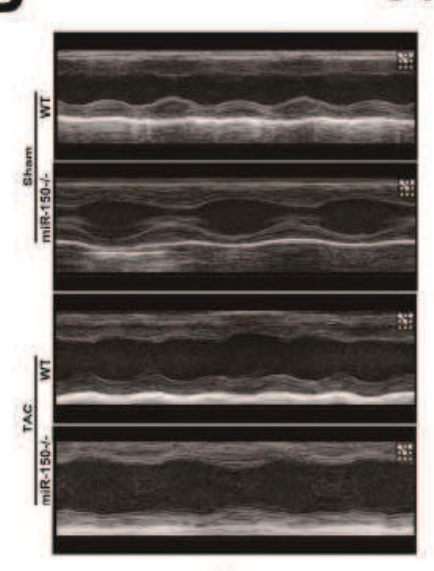

FS

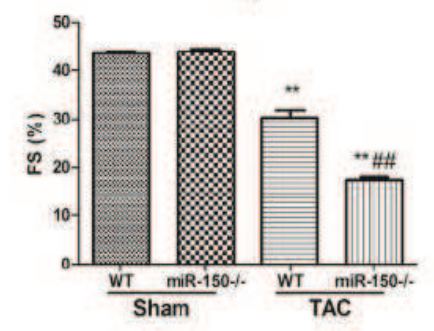

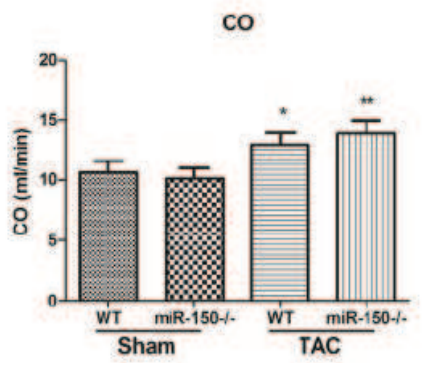

4 Weeks

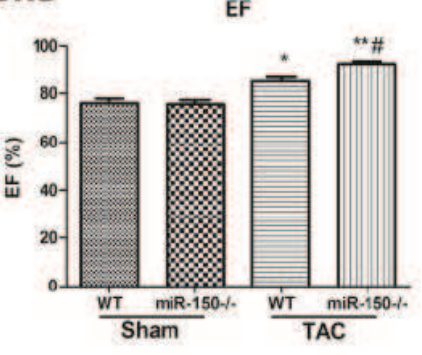

8 Weeks

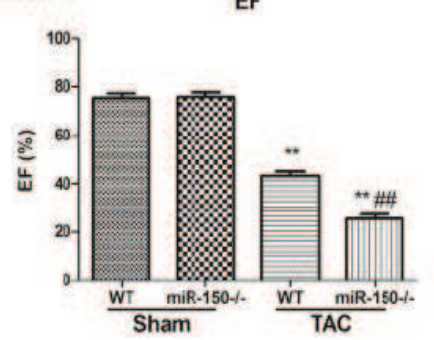

co

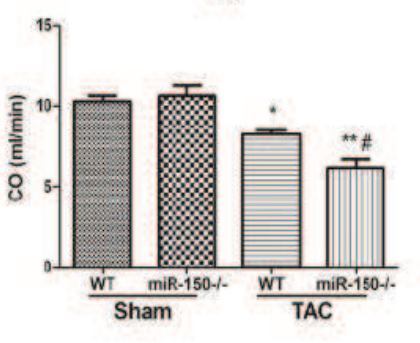

groups exhibited obvious myocardial hypertrophy, and the degree of cardiac hypertrophy in miR-150-/- TAC mice was more severe than was that in WT mice. The left ventricular internal dimensions in systole (LVIDs) and diastole (LVIDd), the left ventricular volume in systole (LV Vols), and the left ventricular fractional shortening (FS) of mice in the TAC groups were reduced significantly, and those of mice in the miR-150-/- TAC group were more 


\section{Cellular Physiology Cell Physiol Biochem 2016;38:2103-2122 \begin{tabular}{l|l|l} 
DOI: 10.1159/000445568 & (c) 2016 The Author(s). Published by S. Karger AG, Basel
\end{tabular} and Biochemistry Published online: May 17, $2016 \quad$ www.karger.com/cpb}

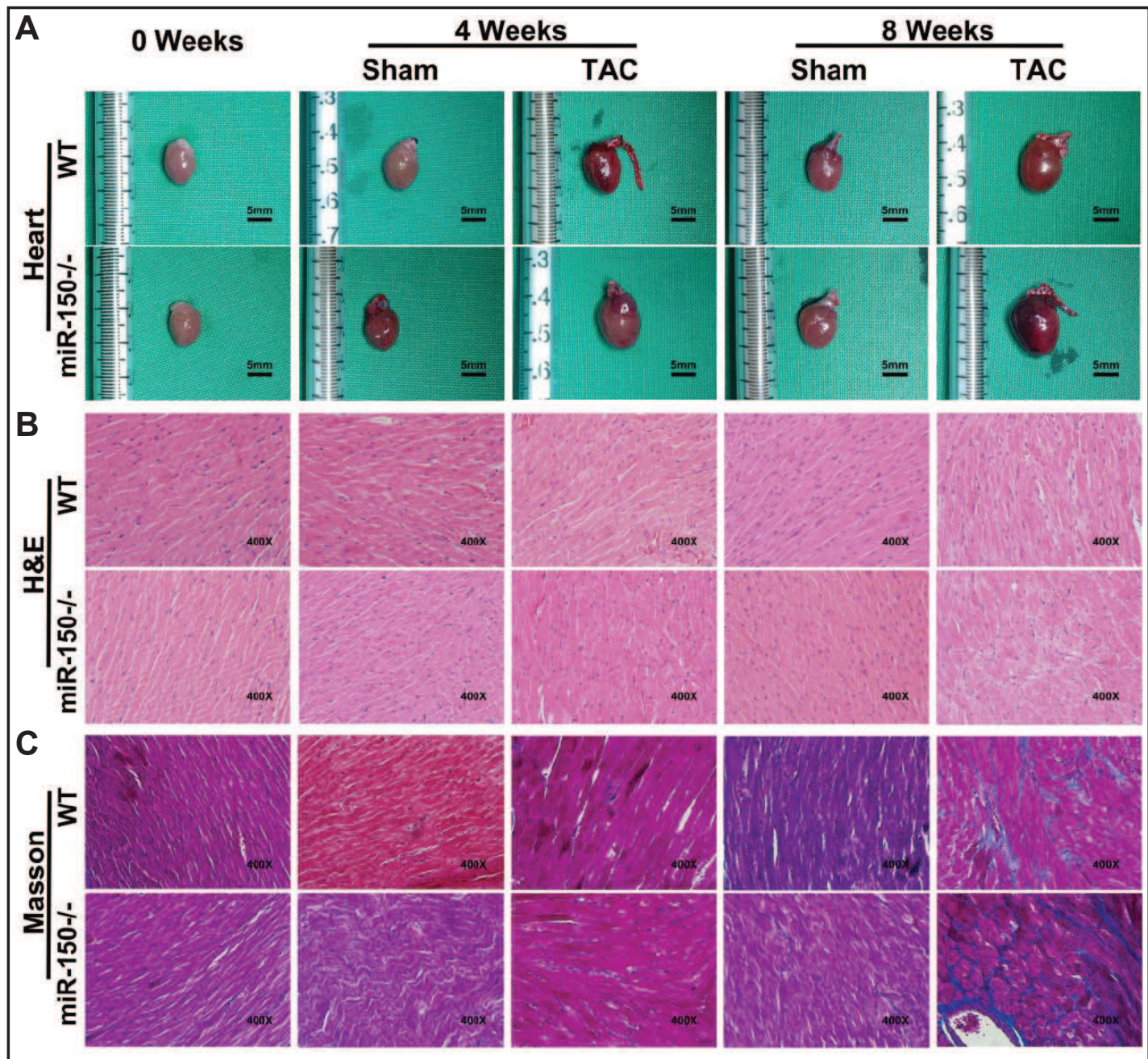

Fig. 3. Pathological analysis of sham and TAC model hearts. (A) The hearts of WT and miR-150-/- mice at 0 , 4 and 8 weeks after the sham or TAC operation. (B) HE staining of hearts at 0,4 and 8 weeks post-TAC in the WT and miR-150-/- groups (original magnification 400×). (C) Masson's trichrome staining of hearts at 0, 4 and 8 weeks post-TAC in the WT and miR-150-/-groups (original magnification 400×).

severely reduced than were those of WT mice. However, the left ventricular volume of the heart in diastole (LV Vold) and stroke volume (SV) did not differ between the groups. The heart rate (HR), EF, cardiac output (CO), and left ventricular posterior wall thickness at the end of systole (LVPWs) and the end of diastole (LVPWd) of the mice in the TAC groups were increased, and mice in the knockout group exhibited the highest values for each of those parameters among all the mice. (Fig. 2A).

In the eighth week, echocardiography showed that mice in the TAC groups exhibited obvious myocardial expansion, and this was observed to be more severe in the miR-150-/mice than in the WT mice. The LVIDs, LVIDd, LV Vold and LV Vols of mice in the TAC groups were significantly increased; additionally, these parameters were more severely increased in the miR-150-/- mice than were those in the WT mice. However, the SV, EF, left ventricular FS, CO, LVPWs and LVPWd of mice in the TAC groups were obviously attenuated, and the miR150-/- mice showed the lowest values (Fig. 2B).

MiR-150 knockout further aggravated cardiac fibrosis in TAC models

To distinguish the differences in cardiac pathology changes between miR-150-/- and WT mice, pathology analysis was performed. The heart volumes and left ventricular and 


\section{Cellular Physiology Cell Physiol Biochem 2016;38:2103-2122 \begin{tabular}{ll|l} 
and Biochemistry & Dublished online: May 17, 2016 & $\begin{array}{l}\text { @ } 2016 \text { The Author(s). Published by S. Karger AG, Basel } \\
\text { www.karger.com/cpb }\end{array}$ \\
\hline
\end{tabular}}

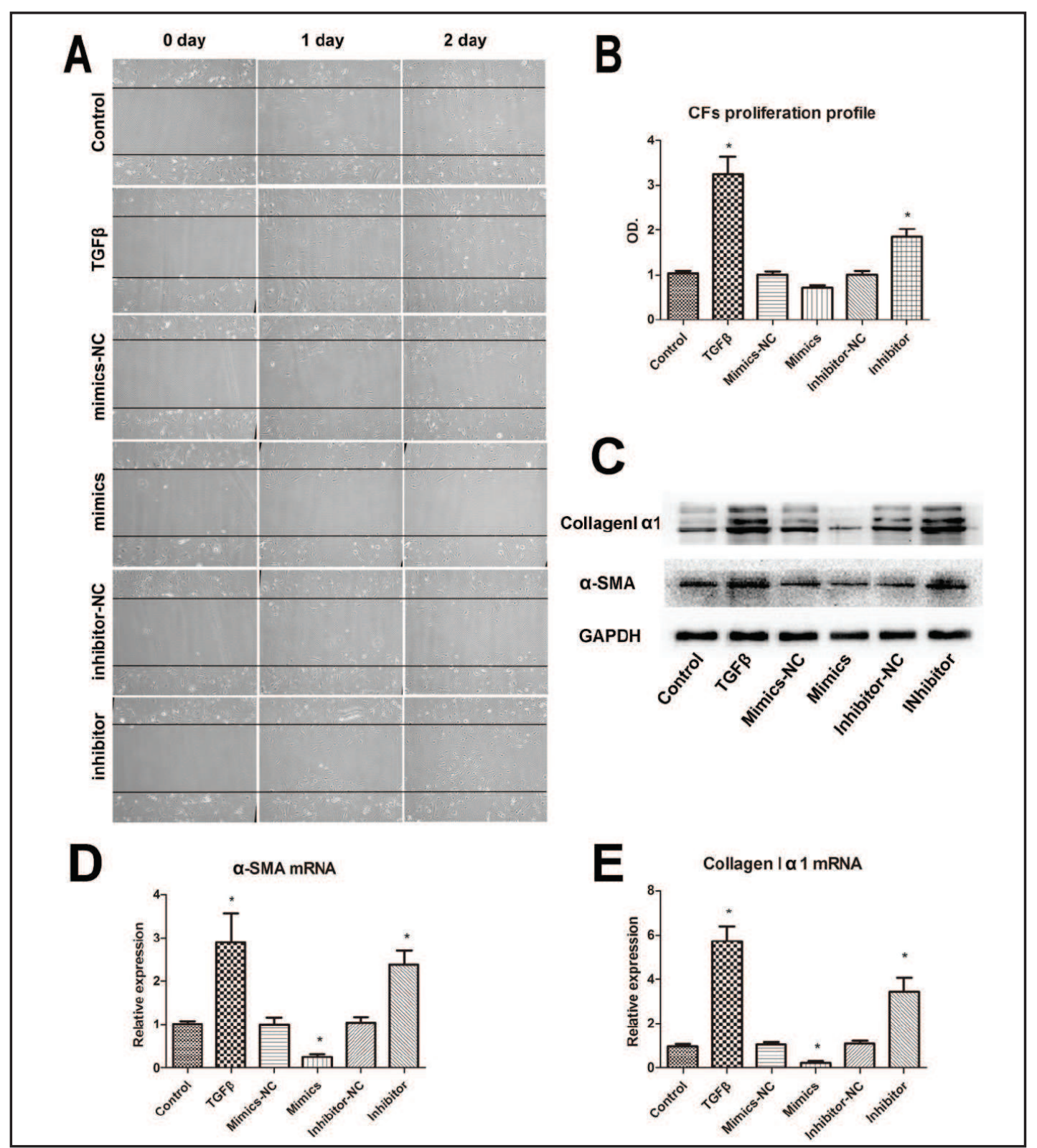

Fig. 4. MiR-150 inhibits CF activation in vitro. (A) Wound healing assay to examine the migratory ability of transfected CFs. MiR-150 mimic inhibits the migratory ability of CFs, whereas the miR-150 inhibitor promotes the migratory ability of CFs. (B) Western blot analysis of collagen I and a-SMA shows that miR-150 mimic inhibits the expression of these proteins in CFs, whereas the miR-150 inhibitor promotes their expression. GAPDH was used as an internal reference. (C) The proliferative abilities of CFs transfected with the miR-150 analogs were examined using a CCK-8 assay. MiR-150 mimic inhibits the proliferation of CFs, whereas the effect of the miR-150 inhibitor was the opposite. (D) and (E), qRT-PCR analysis of collagen I and a-SMA show that the miR-150 mimic reduces mRNA levels in CFs, whereas the miR-150 inhibitor increases their expression. GAPDH was used as an internal reference. ${ }^{*} \mathrm{p}<0.05$ for samples/control.

atrial cavities of the miR-150-/- TAC mice were larger than were those of the WT mice at 4 and 8 weeks (Fig. 3). In the pathological analysis, we observed that mice in the shamoperation groups showed no significant pathological changes, but mice in the TAC groups exhibited serious cardiac remodeling. The cardiomyocyte volume in TAC mice appeared increased, and the array became disordered, particularly at 4 weeks; additionally, this effect 


\section{Cellular Physiology \\ Cell Physiol Biochem 2016;38:2103-2122

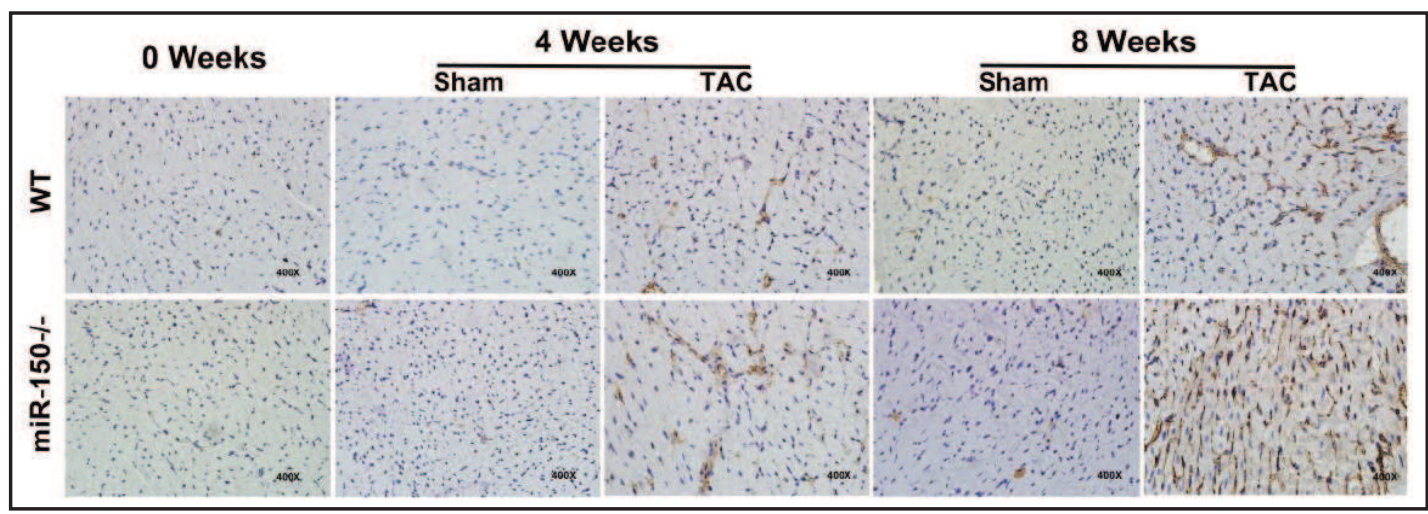

Fig. 5. $\alpha$-SMA expression in myocardial interstitial cells post-TAC as determined by immunohistochemistry. $\alpha$-SMA-positive cells in the myocardial interstitium of WT and miR-150-/- mouse hearts at 0,4 and 8 weeks post-operation (original magnification $400 \times$ ). The number of $\alpha$-SMA-positive cells increased gradually post-operation, and the numbers increased more quickly in the miR-150-/- mice than in the WT mice. Brown indicates the a-SMA, and blue indicates the cellular nucleus.

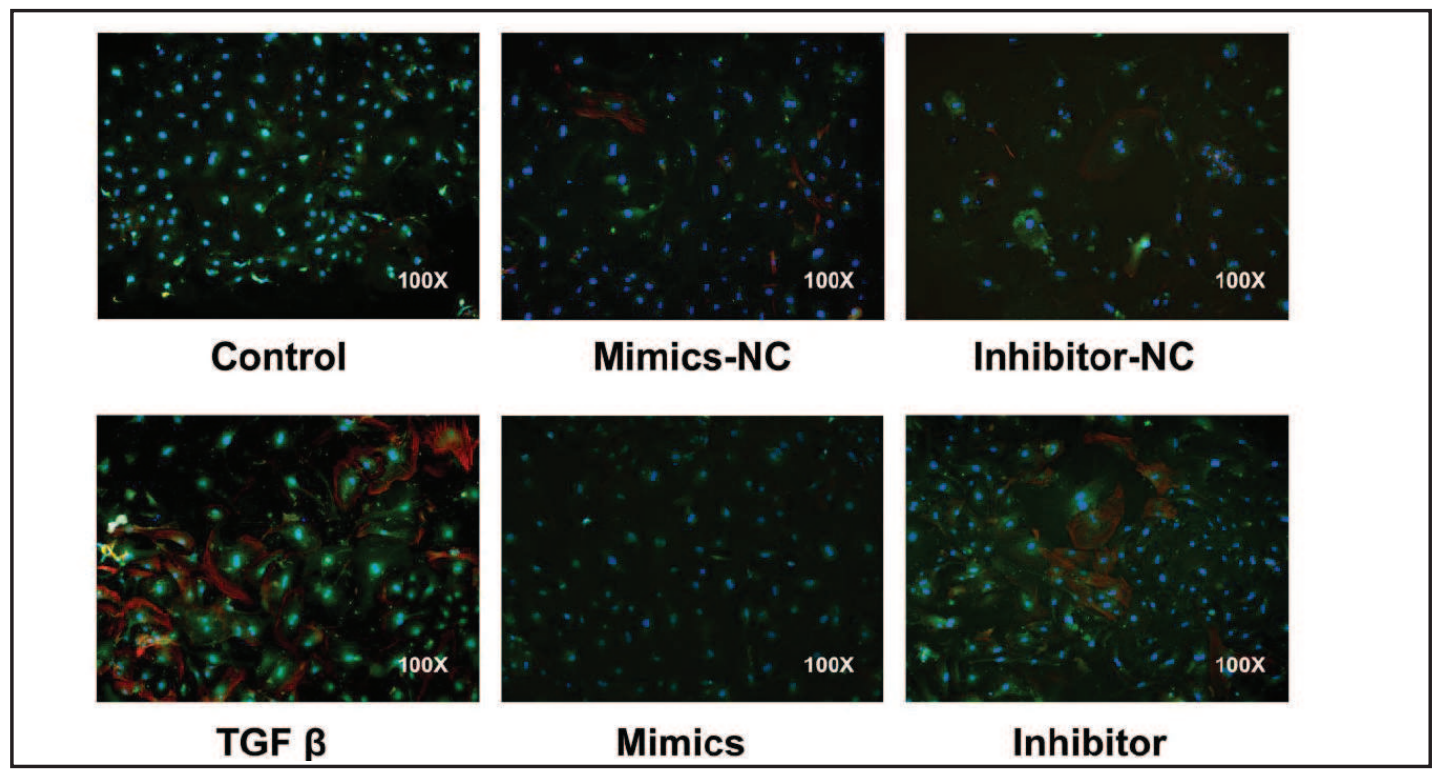

Fig. 6. Immunofluorescence analysis of $\alpha$-SMA expression in cardiac fibroblasts after transfection with miR150 analogs in vitro. Immunofluorescence analysis of $\alpha$-SMA expression in CFs after transfection with miR150 analogs in vitro (original magnification 100×). Under normal conditions, quiescent cardiac fibroblasts barely express $\alpha$-SMA. TGF- $\beta$ and the miR-150 inhibitor promote the expression of $\alpha$-SMA in CFs, and miR150 mimic suppresses a-SMA expression. Blue: cellular nucleus; red: $\alpha$-SMA; green: vimentin, a relatively specific protein marker of fibroblasts.

was observed to be more severe in miR-150-/- mice than in WT mice (Fig. 3). The number of interstitial cells increased over time after the TAC operation, more so in miR-150-/- mice than in WT mice at same time point. However, the number of inflammatory cells infiltrating the myocardial interstitium did not differ significantly among the different groups and time points after TAC (Fig. 3). Masson's trichrome staining showed that fibrosis began around the vessels and that the degree of cardiac fibrosis was increased in the TAC mice with respect to the controls, more so the miR-150-/- mice than in the WT mice (Fig. 3). In addition, immunohistochemical analysis of CD68 in the paraffin cardiac tissue sections of TAC mice showed that the number of CD68-positive cells was not significantly different between the miR-150-/- and WT groups (data not shown). 


\section{Cellular Physiology \\ Cell Physiol Biochem 2016;38:2103-2122

\begin{tabular}{ll|l} 
and Bioch 10.1159/000445568 & $\begin{array}{l}\text { C } 2016 \text { The Author(s). Published by S. Karger AG, Basel } \\
\text { www.karger.com/cpb }\end{array}$ \\
\cline { 2 - 3 }
\end{tabular}

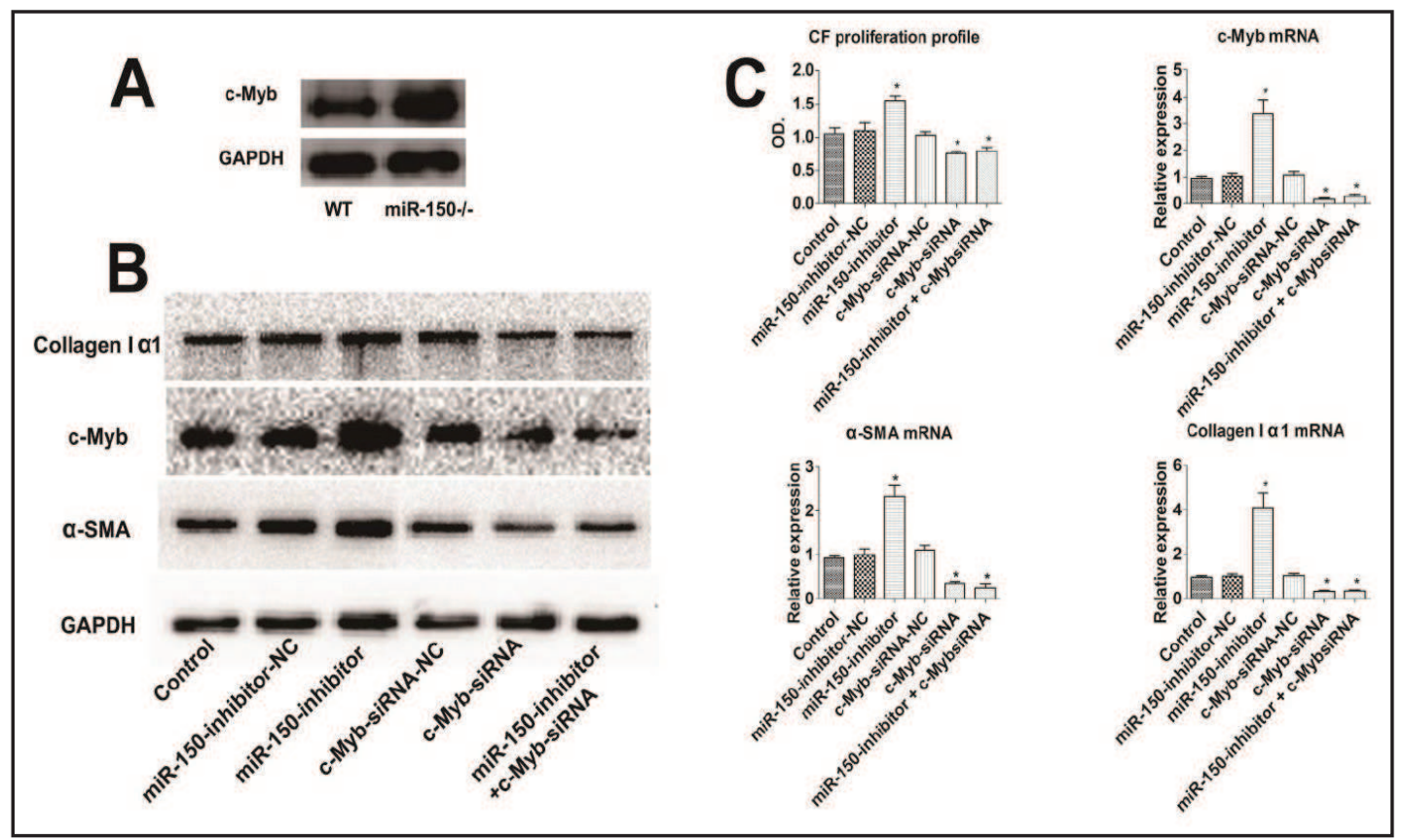

Fig. 7. C-Myb siRNA can inhibit the activation of CFs and suppress the effects of an miR-150 inhibitor. (A) Western blot analysis shows that the expression levels of c-Myb in the hearts of miR-150-/- mice were higher than were those in WT mice. (B) Western blot analysis of collagen I, $\alpha$-SMA and c-Myb shows that the miR-150 inhibitor promoted the expression of collagen I, $\alpha$-SMA and c-Myb in CFs, but the expression of these proteins was significantly suppressed by the c-Myb siRNA. The c-Myb siRNA also eliminated the effect of the miR-150 inhibitor. (C) The proliferative ability of CFs, determined using a CCK-8 assay, was promoted by the miR-150 inhibitor and suppressed by the c-Myb siRNA. The c-Myb siRNA also eliminated the effect of the miR-150 inhibitor. The mRNA expression levels of c-Myb, a-SMA and collagen I in CFs were determined using qRT-PCR analysis. These mRNAs increased with the miR-150 inhibitor and decreased with the c-Myb siRNA. The c-Myb siRNA also eliminated the effect of the miR-150 inhibitor. GAPDH was used as an internal reference. ${ }^{*} \mathrm{p}<0.05$ for samples/control.

\section{MiR-150 downregulation can promote CF activation}

To explore the role of miR-150 in CFs, we had transfected CFs with miR-150 analogs. According to the qRT-PCR results, the intracellular concentration of miR-150 increased by 8000 -fold when the cells were transfected with miR- 150 mimic and decreased by $85 \%$ when the cells were transfected with miR-150 inhibitor (data not shown). When CFs are activated, their abilities to proliferate, migrate and synthesize collagen I are enhanced. Simultaneously, activated CFs express $\alpha$-SMA and differentiate into myofibroblasts. We observed that the number of CFs in the interstitium of cardiac tissue sections from miR-150-/- TAC mice was higher than that in sections from WT mice; therefore, we performed proliferation and migration assays with CFs after the CFs were transfected with analogs. We observed that the miR-150 mimic suppressed CF proliferation and migration. Simultaneously, the miR-150 inhibitor and TGF- $\beta$ promoted CF proliferation and migration (Fig. 4A and C). Western blot analysis indicated that the miR-150 mimic also inhibited collagen I and $\alpha$-SMA expression. TGF- $\beta$ and the miR-150 inhibitor promoted the expression of these proteins in CFs in vitro. The CFs transfected with miRNA-NC did not differ from the control group (Fig. 4B). We also measured the mRNA levels of these proteins; we observed that miR-150 inhibited their expression and that TGF- $\beta$ and the miR-150 inhibitor promoted their expression (Fig. 4D and $\mathrm{E}$ ). To further observe the effect of miR-150 on regulating the differentiation of CFs into myofibroblasts in vivo, we immunohistochemically analyzed the heart tissues of the miR150-/- and TAC mice. The results demonstrated that the myocardial interstitium of the TAC 


\section{Cellular Physiology \\ Cell Physiol Biochem 2016;38:2103-2122 \\ \begin{tabular}{ll|l} 
and Biochemistry Published online: May 17, 2016 & $\begin{array}{l}\text { ○ 2016 The Author(s). Published by S. Karger AG, Basel } \\
\text { www.karger.com/cpb }\end{array}$ \\
\hline
\end{tabular}}

Deng et al.: MicroR-150 Inhibits the Activation of Cardiac Fibroblasts by Regulating c-Myb

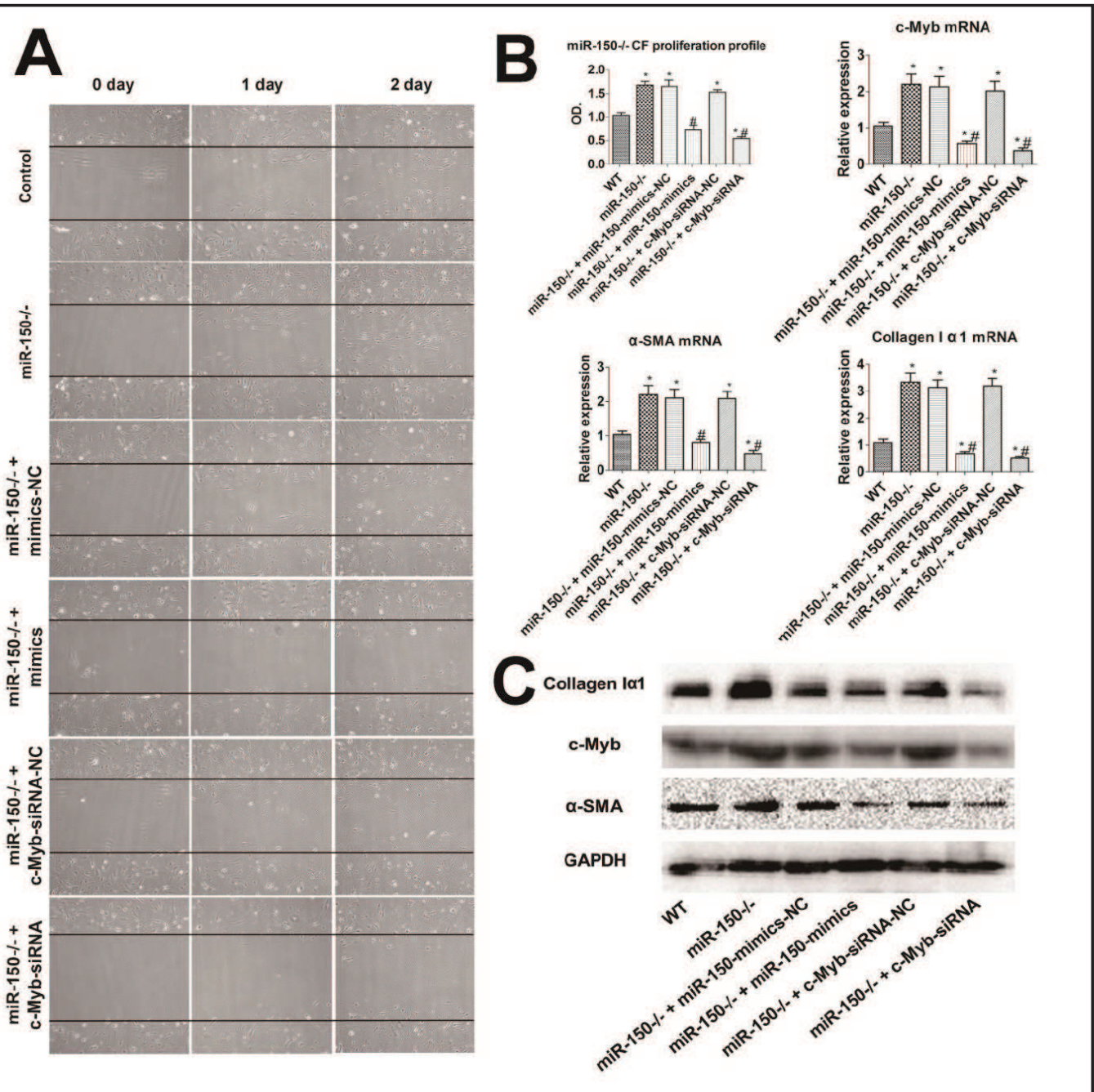

Fig. 8. MiR-150 knockout promoted CF activation in vitro, and c-Myb siRNA suppressed these effects. (A) A scratch assay to examine the migration capabilities of CFs demonstrated that the migratory ability of miR150-/- CFs was significantly stronger than that of WT CFs, and miR-150 mimic and c-Myb siRNA suppressed this ability in miR-150-/- CFs. (B) The proliferative ability of miR-150-/- CFs was significantly stronger than that of WT CFs, as measured by a CCK-8 assay, and miR-150 mimic and c-Myb siRNA suppressed the proliferation of miR-150-/- CFs. The mRNA expression levels of c-Myb, a-SMA and collagen I were determined using qRT-PCR analysis. The expression levels of these mRNAs in miR-150-/- CFs were higher than were those in WT CFs, and miR-150 mimic and c-Myb siRNA suppressed the expression of these mRNAs in miR150-/- CFs. GAPDH was used as an internal reference. (C) Western blot analysis showed that the expression of collagen I, a-SMA and c-Myb in miR-150-/- CFs was higher than was that in WT CFs, and miR-150 mimic and c-Myb siRNA suppressed the expression of these proteins in miR-150-/- CFs. ${ }^{*} \mathrm{p}<0.05$ for samples/WT; \# $\mathrm{p}<0.05$ for samples/ miR-150-/-.

mice contained many $\alpha$-SMA-positive cells that were not present in the normal cardiac interstitium or in tissue from the sham operation group. The number of these cells was highest in the gene knockout group (Fig. 5).

MiR-150 downregulation can induce CFs to differentiate into cardiac myofibroblasts in vitro

CFs can be activated by pathologic stimulation; activated CFs express $\alpha$-SMA and differentiate into myofibroblasts, which are cells that have both smooth muscle cell 


\section{Cellular Physiology Cell Physiol Biochem 2016;38:2103-2122

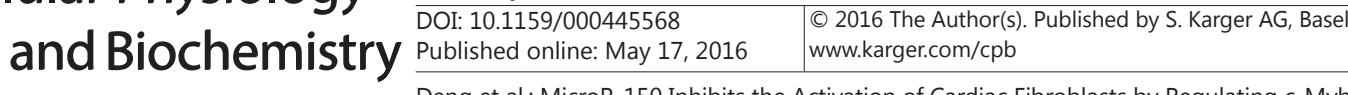 \\ Deng et al.: MicroR-150 Inhibits the Activation of Cardiac Fibroblasts by Regulating c-Myb}

contraction characteristics and the ability of fibroblasts to synthesize ECM, as well as to participate in wound repair and scar formation. We observed that the $\alpha$-SMA expression level was higher in the hearts of miR-150-/- mice compared with those of WT mice after TAC. Therefore, we hypothesized that miR-150 could inhibit $\alpha$-SMA expression in activated CFs. We analyzed $\alpha$-SMA immunofluorescence in CFs after they were transfected with miR-150 analogs; we observed that miR-150 mimic suppressed $\alpha$-SMA expression in activated CFs and that the miR-150 inhibitor and TGF- $\beta$ promoted $\alpha$-SMA expression. As described previously, CFs can be activated to differentiate into myofibroblasts, which are $\alpha$-SMA-positive cells and the primary effector cells in cardiac fibrosis. The number of $\alpha$-SMA-positive cells in cultured CFs transfected with the miR-150 inhibitor and treated with TGF- $\beta$ were highest, and that of CFs transfected with the miR-150 mimic was the lowest (Fig. 6).

\section{MiR-150 regulates CF activation via its target gene, $c-M y b$}

Typically, miRNAs participate in various pathophysiologic processes by regulating their downstream target genes. We used the prediction algorithms TargetScan 6.2 and miRDB to identify 81 potential targets of miR-150. Of these potential targets, c-Myb has been reported to play an important role in fibroblasts. Western blot analysis indicated that c-Myb was overexpressed in the hearts of miR-150-/- mice compared with those of WT mice (Fig. 7A), and c-Myb is constitutively expressed in CFs (Fig. 7B). To ascertain whether miR-150 inhibited $\mathrm{CF}$ activation via c-Myb, we synthesized a small interfering RNA (siRNA) against c-Myb and transfected this siRNA into the CFs. The siRNA inhibited the mRNA and protein expression of c-Myb, and the c-Myb siRNA eliminated the effect of the miR-150 inhibitor. Western blot analysis confirmed that the siRNA eliminated the effect of the miR-150 inhibitor to upregulate the expression of $\alpha$-SMA and collagen I in CFs (Fig. 7B). In addition, qRT-PCR showed that the mRNA levels of these proteins were suppressed to varying degrees. Furthermore, the ability of CFs to proliferate and migrate can be inhibited by this siRNA. (Fig. 7C).

MiR-150 mimic and c-Myb siRNA inhibited the activation of CFs isolated from miR-150-/- mice

To further verify the effect of miR-150 on CF activation, we tested miR-150-/- CFs in vitro. We isolated CFs from miR-150-/- mice, transfected them with an miR-150 analog and c-Myb siRNA, and performed migration and proliferation assays. The migration assay demonstrated that the miR-150-/- CFs had a powerful migratory ability and that the mimic and siRNA inhibited this characteristic (Fig. 8A). The proliferation assay demonstrated that the miR-150-/- CFs proliferated faster than did the WT CFs. Both the mimic and siRNA inhibited this behavior, and the siRNA inhibited it most strongly (Fig. 8B). Western blot and qRT-PCR analyses showed that the miR-150-/- CFs more strongly synthesized c-Myb, collagen I and $\alpha$-SMA compared with the corresponding synthesis levels in the WT CFs; transfection with the mimic and siRNA inhibited this behavior (Fig. 8B and C).

\section{Discussion}

A growing body of evidence suggests that miRNAs play important roles in various cardiovascular diseases, particularly during disease development and progression, and treatments of cardiovascular disease based on miRNAs have important clinical significance [27]. Therefore, the identification of miRNAs that are closely associated with cardiovascular disease is important. Previous reports have shown that the expression levels of miR-150 in cardiac tissues were downregulated in myocardial infarction and cardiac fibrosis induced by pressure overload [20-22]. However, the exact role of miR-150 in these diseases remains unclear. In a previous study, we found that plasma miR-150 levels were significantly associated with atrial fibrillation severity [23]. We also demonstrated that miR-150 disturbs the inflammatory response of peripheral blood monocytes in myocardial infarction by 


\section{Cellular Physiology Cell Physiol Biochem 2016;38:2103-2122 \\ \begin{tabular}{ll|l} 
DOI: 10.1159/000445568 & $\begin{array}{l}\text { @ } 2016 \text { The Author(s). Published by S. Karger AG, Basel } \\
\text { www.karger.com/cpb }\end{array}$ \\
\cline { 2 - 4 }
\end{tabular}}

targeting CXCR4 [24]. These results suggest that miR-150 in peripheral blood can regulate the occurrence and development of cardiovascular diseases, such as myocardial infarction. We next asked whether the local miR-150 levels in cardiac issue were involved in cardiac fibrosis.

To address this question, we created TAC models using WT mice and observed that miR150 expression levels in the left ventricle were downregulated significantly during the early stages after TAC, with the largest decline of nearly two-thirds occurring at 2 and 4 weeks; the expression levels then began to return to baseline, but they remained below normal levels. In previous reports, the expression levels of miR-150 in hypertrophic heart tissue were reduced [20, 28-30]. In our study, we further validated this phenomenon and, for the first time, revealed the expression pattern of miR-150 in myocardial hypertrophy induced by pressure overload. Therefore, we posit that either this change in miR-150 expression is an epiphenomenon or miR-150 is a regulatory molecule of cardiac fibrosis induced by pressure overload. To further explore the role of miR-150 in vivo, we constructed TAC models using miR-150-/- and WT mice. By measuring the cardiac function and pathological changes at 4 and 8 weeks post-operation, we observed that the cardiac function of miR-150-/- and WT sham-operation mice were normal and were not significantly different. In addition, knocking out miR-150 promoted the occurrence and development of myocardial hypertrophy, cardiac fibrosis and heart failure. These results suggest that miR-150 is a protective regulator rather than a responder and that miR-150 deficiency promotes the occurrence and progression of pressure overload-induced cardiac fibrosis, which at least partially promotes the progression of cardiac fibrosis.

In previous reports, miR-150 was specifically expressed in mature lymphocytes and subsequently controlled the development of B cells, NK cells and iNKT cells via the transcription factor c-Myb [31, 32]. By immunohistochemically analyzing the heart tissue of miR-150-/- and WT TAC mice, we observed few CD68-positive cells in the myocardial mesenchyme of the two groups, and the numbers of CD68-positive cells were not significantly different. This result suggests that the effect of miR-150 deficiency on inflammatory cells was not the main cause of the increased myocardial fibrosis severity observed in miR-150/- TAC mice compared with that in WT mice.

During the cardiac remodeling induced by pressure overload, the main pathological changes were cardiomyocyte hypertrophy and interstitial fibrosis, and the main effector cells were cardiomyocytes and CFs. Therefore, we investigated in which cells miR-150 was involved. We isolated cardiomyocytes and CFs from the WT TAC mice at different time points and quantified the miR-150 expression levels in these cells. The novel results showed that the miR-150 expression levels in CFs were higher than were those in myocardial cells, and the fluctuation range in CFs was larger than that in cardiomyocytes. Therefore, we posit that miR-150 in CFs has a major regulatory effect on pressure overload-induced cardiac fibrosis. However, it seems contradictory that the expression levels of miR-150, a protective regulator for the heart, began to return to baseline in CFs four weeks after the TAC operation, while the degrees of cardiac fibrosis and heart failure were aggravated. This outcome might be associated with the expression level of miR-150 that remained below the baseline level, as well as the damaging effect of decreased miR-150 expression that did not completely disappear. This phenomenon might also be related to the different functional statuses of CFs during the occurrence and development of the disease. However, the causes of increased miR-150 expression remain to be determined through further research.

During this after-load increase, cardiomyocytes and CFs can be activated by increased mechanical tension of the left ventricular wall. Cardiac stress triggers cardiomyocyte hypertrophy, whereas CFs start to proliferate and secrete ECM proteins and proinflammatory cytokines, resulting in cardiac fibrosis [33, 34]. Cardiac fibroblasts can be activated within 24 hours after the load increases, and their ability to synthesize collagen becomes enhanced [35]. These fibroblast-derived mediators facilitate cardiac remodeling through autocrine and paracrine mechanisms between fibroblasts and cardiomyocytes [36, 37]. Furthermore, 


\section{Cellular Physiology Cell Physiol Biochem 2016;38:2103-2122 \\ \begin{tabular}{ll|l} 
DOI: 10.1159/000445568 & $\begin{array}{l}\text { ( ) } 2016 \text { The Author(s). Published by S. Karger AG, Basel } \\
\text { www.karger.com/cpb }\end{array}$ \\
\cline { 2 - 4 }
\end{tabular}}

Deng et al.: MicroR-150 Inhibits the Activation of Cardiac Fibroblasts by Regulating c-Myb

adult murine cardiomyocytes experience hypertrophy when they are co-cultured with CFs or treated with conditioned media from fibroblast cultures [38, 39]. However, the underlying mechanisms of communication between fibroblasts and cardiomyocytes are not yet fully understood.

In the current study, we observed that the degrees of myocardial hypertrophy and cardiac fibrosis in miR-150-/- TAC mice were more serious than in the WT mice. The expression levels of miR-150 in CFs were significantly higher than were those in cardiomyocytes, and a larger fluctuation range of miR-150 in CFs was observed in pressure-overloaded mice than in WT mice; thus, we speculated that miR-150 was mainly involved in the CFs. Under pressure overload, the lack of miR-150 promoted the excessive activation of CFs in miR-150-/- TAC mice, and excessively activated CFs resulted in the occurrence of interstitial fibrosis and triggered myocardial hypertrophy. These outcomes potentially explain why the degrees of myocardial hypertrophy and interstitial fibrosis in miR-150-/- TAC mice were more severe than were those in WT mice. Previous reports have shown that cardiac fibroblast-derived miRNA passenger strand-enriched exosomes mediate cardiomyocyte hypertrophy [40]. However, determining how the miR-150-/- CFs promote myocardial hypertrophy requires further study. The fibroblasts that participate in cardiac fibrosis have multiple origins, including CFs, endotheliocytes, smooth muscle cells, vascular pericytes and fibrocytes in peripheral blood [41]. Previous reports have suggested that the resident CFs are the primary effector cells for pressure overload-induced cardiac fibrosis [42]. Thus, we focused primarily on the role of miR-150 in CFs in pressure overload-induced cardiac fibrosis.

To explore the role of miR-150 in CFs, we isolated and cultured CFs from WT mice and transfected them with miR-150 mimic and inhibitor. Under pathological conditions, the ability of CFs to proliferate, migrate and secrete ECM was greatly enhanced after activation, and activated cardiac fibroblasts can also differentiate into myofibroblasts. A critical event in cardiac fibrosis is the transformation of activated CFs into myofibroblasts. Through transfection experiments, we demonstrated that the miR-150 mimic inhibited CF proliferation, migration and collagen I synthesis. In contrast, the miR-150 inhibitor, similar to TGF- $\beta$, enhanced these CF functions. Pathologically, some activated fibroblasts will differentiate into myofibroblasts, which become $\alpha$-SMA-positive and have a stronger ability to synthesize ECM and contract scar tissue. However, the miR-150 mimic inhibited myofibroblast differentiation. The miR-150 inhibitor and TGF- $\beta$ promoted the differentiation of CFs into myofibroblasts. The immunohistochemical analysis of $\alpha$-SMA in the cardiac tissue of miR-150-/- and WT TAC mice further confirmed the effects of miR-150 on myofibroblast differentiation. These in vivo and in vitro results suggest that miR-150 inhibits $\mathrm{CF}$ activation.

We then used TargetScan 6.2 and miRDB to predict the target of miR-150, and we discovered that miR-150 had 81 potential targets. Of these potential targets, c-Myb was one of the top targets predicted for miR-150 [43] and is a critical transcription factor for lymphocyte development under normal conditions [44, 45]. MiR-150 partially blocked the development of B cells by directly regulating c-Myb protein levels through two conserved miR-150 binding sites in the 3'UTR of the c-Myb mRNA [31]. In addition, miR-150 can increase NK and decrease iNKT cell development [32]. C-Myb also plays an important role in fibroblasts. Previous studies have found that c-Myb could strongly and specifically transactivate the promoter of collagen I- $\mathrm{a} 2$ to upregulate type I collagen gene expression in normal human skin fibroblasts and mouse embryonic fibroblasts [46, 47]. C-Myb knockout is a fatal genetic mutation, and c-Myb-/- mouse embryonic skin is markedly thinner than normal; in addition, collagen type I is completely absent. The skin of heterozygous c-Mybdeficient mice exhibits impaired wound-repair capability and reduced collagen type I levels. C-Myb-deficient wounds show reduced fibroblast cell proliferation and collagen levels, but the TGF- $\beta 1$ expression levels are elevated [48]. Ma $\mathrm{HH}$ et al. have reported that the antisense RNA of c-Myb suppressed collagen I-a1 expression in cultured hepatic stellate cells [49]. Additionally, because c-Myb was hypothesized to play a critical role in CFs [50], we speculated that c-Myb not only has an important role in the activation of CFs but also is the target of miR-150 that mediates $\mathrm{CF}$ activation. 


\section{Cellular Physiology Cell Physiol Biochem 2016;38:2103-2122 \\ \begin{tabular}{ll|l} 
DOI: 10.1159/000445568 & $\begin{array}{l}\text { @ } 2016 \text { The Author(s). Published by S. Karger AG, Basel } \\
\text { www.karger.com/cpb }\end{array}$ \\
\cline { 2 - 4 }
\end{tabular}}

Myofibroblasts have features of both fibroblasts and smooth muscle cells. The emergence of $\alpha$-SMA in fibroblasts is typically a sign of fibroblast differentiation into myofibroblasts. Previous studies have reported that c-Myb modulates the transcription of the alpha-smooth muscle actin gene in activated hepatic stellate cells [51] and can also promote precursor stem cell differentiation into smooth muscle cells [52]. Therefore, we speculated that c-Myb can also promote the differentiation of CFs into myofibroblasts.

Western blot and qRT-PCR analyses indicated that c-Myb was overexpressed in the cardiac tissues of miR-150-/- mice compared with those of WT mice and that it was constitutively expressed in CFs. Simultaneously, transfecting miR-150 into CFs suppressed the expression of c-Myb. Therefore, we speculated that miR-150 can regulate the expression of c-Myb in cardiac tissue and CFs. Recent reports have described that miR-150 could protect the heart against pressure overload-induced cardiac hypertrophy by targeting the serum response factor (SRF) [53]. However, the authors did not further investigate why the degree of cardiac hypertrophy observed in miR-150-/- TAC mice was more serious than that in WT mice. Silencing SRF is also necessary to further validate the role of SRF in the process of miR-150 protecting the heart against cardiac hypertrophy. In this study, we demonstrated for the first time that miR-150 suppresses cardiac fibrosis via c-Myb. Tang Y et al. previously reported that miR-150 could repress the ischemia-induced apoptosis of cardiomyocytes by repressing the proapoptotic genes ERG2 (zinc-binding transcription factor induced by ischemia) and P2X7R (pro-inflammatory ATP receptor) [54]. The underlying mechanisms of cardiac fibrosis in different diseases are different, but there are some commonalities. During cardiac fibrosis, hypertrophic cardiomyocytes can undergo apoptosis, and the resulting debris can activate CFs and trigger interstitial fibrosis [55, 56]. However, the roles of ERG2 and P2X7R in cardiac fibrosis induced by pressure overload require further research.

To further verify the role of c-Myb in CF activation, we synthesized an siRNA against $\mathrm{c}-\mathrm{Myb}$ and used it to transfect CFs in vitro. The siRNA significantly reduced the expression levels of c-Myb mRNA and protein. This result suggested that the siRNA promoted the degradation of c-Myb mRNA and subsequently caused a decrease in c-Myb protein expression within the cells. Fibroblast activation was significantly suppressed by the c-Myb siRNA. The expression level of $\alpha$-SMA and the differentiation of myofibroblasts were remarkably decreased after transfection with siRNA. In addition, when CFs were co-transfected with an miR-150 inhibitor and c-Myb siRNA, c-Myb siRNA eliminated the effect of the miR-150 inhibitor. These data suggest that c-Myb is one of the targets of miR-150 that regulates CF activation. Next, we determined whether this type of regulation also existed in miR-150 knockout mice. We isolated CFs from miR-150-/- and WT mice and found that the abilities of miR-150-/- CFs to proliferate, migrate and synthesize collagen I were significantly stronger than those of WT CFs. These CFs also differentiated more easily into myofibroblasts. The c-Myb siRNA inhibited these characteristics of the miR-150-/- CFs. In conclusion, c-Myb is a critical target through which miR-150 regulates the participation of CFs in cardiac fibrosis.

In summary, our study reveals, for the first time, the expression pattern of miR-150 in myocardial hypertrophy induced by pressure overload. We first isolated cardiomyocytes and CFs from pressure-overloaded hearts at different time points, and we then measured the miR-150 expression levels in these cells. We observed that miR-150 expression levels were reduced significantly in CFs and fluctuated only slightly in cardiomyocytes. Through both in vitro and in vivo experiments, we demonstrated that miR-150 can protect the heart against pressure overload-induced cardiac fibrosis by inhibiting the activation of CFs. By analyzing the targets of miR-150, we identified a novel target of miR-150, i.e., c-Myb. C-Myb is a critical transcription factor in cancer and lymphocytes. We demonstrate, for the first time, the involvement of c-Myb in cardiac fibroblast and cardiac fibrosis. We identified a novel regulatory pathway through which miR-150 can inhibit fibroblast activation by regulating the transcription factor c-Myb and then protect the heart against cardiac fibrosis. This study offers a new approach towards prevent cardiac fibrosis induced by pressure overload, as well as subsequent heart failure, and provides a theoretical basis for clinical decision-making. 


\section{Cellular Physiology \\ Cell Physiol Biochem 2016;38:2103-2122 \\ \begin{tabular}{l|l}
\hline DOI: $10.1159 / 000445568$ & (c) 2016 The Author(s). Published by S. Karger AG, Basel
\end{tabular} and Biochemistry Published online: May 17, 2016 www.karger.com/cpb \\ Deng et al.: MicroR-150 Inhibits the Activation of Cardiac Fibroblasts by Regulating c-Myb}

\section{Abbreviations}

CF (cardiac fibroblast); miRNA (MicroRNA); AMI (acute myocardial infarction); TAC (transverse aortic constriction); WT (wild type); ECM (extracellular matrix); qRT-PCR (Quantitative reverse transcription-polymerase chain reaction); NC (negative control); siRNA (small interfering RNA); TGF- $\beta$ (transforming growth factor- $\beta$ ); $\alpha$-SMA (alphasmooth muscle actin); LVIDs (left ventricular internal dimensions in systole); LVIDd (left ventricular internal dimensions in diastole); LV Vold (left ventricular volume of the heart in diastole); LV Vols (left ventricular volume of the heart in systole); SV (stroke volume); EF (Ejection Fraction); CO (cardiac output); FS (left ventricular fractional shortening); LVPWs (left ventricular posterior wall thicknesses at the end of systole); LVPWd (left ventricular posterior wall thicknesses at the end of diastole).

\section{Acknowledgements}

This work was supported by grants from the National Natural Science Foundation of China (81470482) and the Key Technology Research Project of Wuhan City (2013060602010256).

\section{Disclosure Statement}

The authors have no competing interests to declare.

\section{References}

1 Camelliti P, Borg TK, Kohl P: Structural and functional characterisation of cardiac fibroblasts. Circ Res 2005;65:40-51.

2 Souders CA, Bowers SL, Baudino TA: Cardiac fibroblast: The renaissance cell. Circ Res 2009;105:11641176.

3 Abramochkin DV, Lozinsky IT, Kamkin A: Influence of mechanical stress on fibroblast-myocyte interactions in mammalian heart. J Mol cell Cardiol 2014;70:27-36.

4 Porter KE, Turner NA: Cardiac fibroblasts: At the heart of myocardial remodeling. Pharmacol Ther 2009;123:255-278.

5 Ubil E, Duan J, Pillai IC, Rosa-Garrido M, Wu Y, Bargiacchi F, Lu Y, Stanbouly S, Huang J, Rojas M, Vondriska TM, Stefani E, Deb A: Mesenchymal-endothelial transition contributes to cardiac neovascularization. Nature 2014;514:585-590.

6 Shinde AV, Frangogiannis NG: Fibroblasts in myocardial infarction: A role in inflammation and repair. J Mol Cell Cardiol 2014;70:74-82.

7 Chaturvedi RR, Herron T, Simmons R, Shore D, Kumar P, Sethia B, Chua F, Vassiliadis E, Kentish JC: Passive stiffness of myocardium from congenital heart disease and implications for diastole. Circulation 2010;121:979-988.

8 Kai H, Mori T, Tokuda K, Takayama N, Tahara N, Takemiya K, Kudo H, Sugi Y, Fukui D, Yasukawa H, Kuwahara F, Imaizumi T: Pressure overload-induced transient oxidative stress mediates perivascular inflammation and cardiac fibrosis through angiotensin II. Hypertens Res 2006;29:711-718.

9 Bartel DP: Micrornas: Genomics, biogenesis, mechanism, and function. Cell 2004;116:281-297.

10 Lewis BP, Burge CB, Bartel DP: Conserved seed pairing, often flanked by adenosines, indicates that thousands of human genes are microrna targets. Cell 2005;120:15-20.

11 Ambros V: The functions of animal micrornas. Nature 2004;431:350-355.

12 Kloosterman WP, Plasterk RH: The diverse functions of micrornas in animal development and disease. Dev Cell 2006;11:441-450.

13 Hata A: Functions of micrornas in cardiovascular biology and disease. Annu Rev Physiol 2013;75:69-93. 


\section{Cellular Physiology Cell Physiol Biochem 2016;38:2103-2122 \begin{tabular}{c|l} 
DOI: 10.1159/000445568 & $\begin{array}{l}\text { @ } 2016 \text { The Author(s). Published by S. Karger AG, Basel } \\
\text { www.karger.com/cpb }\end{array}$ \\
\cline { 2 - 3 }
\end{tabular}}

Deng et al.: MicroR-150 Inhibits the Activation of Cardiac Fibroblasts by Regulating c-Myb

14 Condorelli G, Latronico MV, Cavarretta E: Micrornas in cardiovascular diseases: Current knowledge and the road ahead. J Am Coll Cardiol 2014;63:2177-2187.

15 Zhao X, Wang K, Liao Y, Zeng Q, Li Y, Hu F, Liu Y, Meng K, Qian C, Zhang Q, Guan H, Feng K, Zhou Y, Du Y, Chen Z: Microrna-101a inhibits cardiac fibrosis induced by hypoxia via targeting tgfbetari on cardiac fibroblasts. Cell Physiol Biochem 2015;35:213-226.

16 Melo SF, Fernandes T, Barauna VG, Matos KC, Santos AA, Tucci PJ, Oliveira EM: Expression of microrna-29 and collagen in cardiac muscle after swimming training in myocardial-infarcted rats. Cell Physiol Biochem 2014;33:657-669.

17 van Rooij E, Olson EN: Micrornas: Powerful new regulators of heart disease and provocative therapeutic targets. J Clin Invest 2007;117:2369-2376.

18 Tijsen AJ, Pinto YM, Creemers EE: Circulating micrornas as diagnostic biomarkers for cardiovascular diseases. Am J Physiol Heart Circ Physiol 2012;303:H1085-1095.

19 Gupta SK, Bang C, Thum T: Circulating micrornas as biomarkers and potential paracrine mediators of cardiovascular disease. Circ Cardiovasc Genet 2010;3:484-488.

20 van Rooij E, Sutherland LB, Liu N, Williams AH, McAnally J, Gerard RD, Richardson JA, Olson EN: A signature pattern of stress-responsive micrornas that can evoke cardiac hypertrophy and heart failure. Proc Natl Acad Sci U S A 2006;103:18255-18260.

21 Devaux Y, Vausort M, McCann GP, Zangrando J, Kelly D, Razvi N, Zhang L, Ng LL, Wagner DR, Squire IB: Microrna-150: A novel marker of left ventricular remodeling after acute myocardial infarction. Circ Cardiovasc Genet 2013;6:290-298.

22 van Rooij E, Sutherland LB, Thatcher JE, DiMaio JM, Naseem RH, Marshall WS, Hill JA, Olson EN: Dysregulation of micrornas after myocardial infarction reveals a role of mir-29 in cardiac fibrosis. Proc Natl Acad Sci U S A 2008;105:13027-13032.

23 Liu Z, Zhou C, Liu Y, Wang S, Ye P, Miao X, Xia J: The expression levels of plasma micornas in atrial fibrillation patients. PLoS One 2012;7:e44906.

24 Liu Z, Ye P, Wang S, Wu J, Sun Y, Zhang A, Ren L, Cheng C, Huang X, Wang K, Deng P, Wu C, Yue Z, Xia J: Microrna-150 protects the heart from injury by inhibiting monocyte accumulation in a mouse model of acute myocardial infarction. Circ Cardiovasc Genet 2015;8:11-20.

25 Huang ZP, Chen J, Seok HY, Zhang Z, Kataoka M, Hu X, Wang DZ: Microrna-22 regulates cardiac hypertrophy and remodeling in response to stress. Circ Res 2013;112:1234-1243.

26 Pan Z, Sun X, Shan H, Wang N, Wang J, Ren J, Feng S, Xie L, Lu C, Yuan Y, Zhang Y, Wang Y, Lu Y, Yang B: Microrna-101 inhibited postinfarct cardiac fibrosis and improved left ventricular compliance via the fbj osteosarcoma oncogene/transforming growth factor-beta1 pathway. Circulation 2012;126:840-850.

27 Yin K, Zhao L, Feng D, Ma W, Liu Y, Wang Y, Liang J, Yang F, Bi C, Chen H, Li X, Lu Y, Cai B: Resveratrol attenuated low ambient temperature-induced myocardial hypertrophy via inhibiting cardiomyocyte apoptosis. Cell Physiol Biochem 2015;35:2451-2462.

28 Sayed D, Hong C, Chen IY, Lypowy J, Abdellatif M: Micrornas play an essential role in the development of cardiac hypertrophy. Circ Res 2007;100:416-424.

29 Cheng Y, Ji R, Yue J, Yang J, Liu X, Chen H, Dean DB, Zhang C: Micrornas are aberrantly expressed in hypertrophic heart: Do they play a role in cardiac hypertrophy? Am J Pathol 2007;170:1831-1840.

30 Tatsuguchi M, Seok HY, Callis TE, Thomson JM, Chen JF, Newman M, Rojas M, Hammond SM, Wang DZ: Expression of micrornas is dynamically regulated during cardiomyocyte hypertrophy. J Mol Cell Cardiol 2007;42:1137-1141.

31 Xiao C, Calado DP, Galler G, Thai TH, Patterson HC, Wang J, Rajewsky N, Bender TP, Rajewsky K: Mir-150 controls b cell differentiation by targeting the transcription factor c-myb. Cell 2007;131:146-159.

32 Bezman NA, Chakraborty T, Bender T, Lanier LL: Mir-150 regulates the development of nk and inkt cells. J Exp Med 2011;208:2717-2731.

33 Pimentel DR, Adachi T, Ido Y, Heibeck T, Jiang B, Lee Y, Melendez JA, Cohen RA, Colucci WS: Strainstimulated hypertrophy in cardiac myocytes is mediated by reactive oxygen species-dependent ras s-glutathiolation. J Mol Cell Cardiol 2006;41:613-622.

34 Oka T, Komuro I: Molecular mechanisms underlying the transition of cardiac hypertrophy to heart failure. Circ J 2008;72 Suppl A:A13-16.

35 Carver W, Nagpal ML, Nachtigal M, Borg TK, Terracio L: Collagen expression in mechanically stimulated cardiac fibroblasts. Circ Res 1991;69:116-122. 


\section{Cellular Physiology Cell Physiol Biochem 2016;38:2103-2122 \begin{tabular}{ll|l} 
DOI: 10.1159/000445568 & $\begin{array}{l}\text { () 2016 The Author(s). Published by S. Karger AG, Base } \\
\text { www.karger.com/cpb }\end{array}$ \\
\cline { 2 - 3 } & Published online: May 17, 2016 & and Biochemistry
\end{tabular}}

Deng et al.: MicroR-150 Inhibits the Activation of Cardiac Fibroblasts by Regulating c-Myb

36 Takeda N, Manabe I, Uchino Y, Eguchi K, Matsumoto S, Nishimura S, Shindo T, Sano M, Otsu K, Snider P, Conway SJ, Nagai R: Cardiac fibroblasts are essential for the adaptive response of the murine heart to pressure overload. J Clin Invest 2010;120:254-265.

37 Kakkar R, Lee RT: Intramyocardial fibroblast myocyte communication. Circ Res 2010;106:47-57.

38 Fredj S, Bescond J, Louault C, Potreau D: Interactions between cardiac cells enhance cardiomyocyte hypertrophy and increase fibroblast proliferation. J Cell Physiol 2005;202:891-899.

39 LaFramboise WA, Scalise D, Stoodley P, Graner SR, Guthrie RD, Magovern JA, Becich MJ: Cardiac fibroblasts influence cardiomyocyte phenotype in vitro. Am J Physiol Cell Physiol 2007;292:C1799-1808.

40 Bang C, Batkai S, Dangwal S, Gupta SK, Foinquinos A, Holzmann A, Just A, Remke J, Zimmer K, Zeug A, Ponimaskin E, Schmiedl A, Yin X, Mayr M, Halder R, Fischer A, Engelhardt S, Wei Y, Schober A, Fiedler J, Thum T: Cardiac fibroblast-derived microrna passenger strand-enriched exosomes mediate cardiomyocyte hypertrophy. J Clin Invest 2014;124:2136-2146.

41 Lajiness JD, Conway SJ: Origin, development, and differentiation of cardiac fibroblasts. J Mol Cell Cardiol 2014;70:2-8.

42 Moore-Morris T, Guimaraes-Camboa N, Banerjee I, Zambon AC, Kisseleva T, Velayoudon A, Stallcup WB, Gu Y, Dalton ND, Cedenilla M, Gomez-Amaro R, Zhou B, Brenner DA, Peterson KL, Chen J, Evans SM: Resident fibroblast lineages mediate pressure overload-induced cardiac fibrosis. J Clin Invest 2014;124:2921-2934.

43 Krek A, Grun D, Poy MN, Wolf R, Rosenberg L, Epstein EJ, MacMenamin P, da Piedade I, Gunsalus KC, Stoffel M, Rajewsky N: Combinatorial microrna target predictions. Nat Genet 2005;37:495-500.

44 Bender TP, Kremer CS, Kraus M, Buch T, Rajewsky K: Critical functions for c-myb at three checkpoints during thymocyte development. Nat Immunol 2004;5:721-729.

45 Thomas MD, Kremer CS, Ravichandran KS, Rajewsky K, Bender TP: C-myb is critical for b cell development and maintenance of follicular b cells. Immunity 2005;23:275-286.

46 Piccinini G, Golay J, Flora A, Songia S, Luchetti M, Gabrielli A, Introna M: C-myb, but not b-myb, upregulates type i collagen gene expression in human fibroblasts. J Invest Dermatol 1999;112:191-196.

47 Luchetti MM, Paroncini P, Majlingova P, Frampton J, Mucenski M, Baroni SS, Sambo P, Golay J, Introna M, Gabrielli A: Characterization of the c-myb-responsive region and regulation of the human type i collagen alpha 2 chain gene by c-myb. J Biol Chem 2003;278:1533-1541.

48 Kopecki Z, Luchetti MM, Adams DH, Strudwick X, Mantamadiotis T, Stoppacciaro A, Gabrielli A, Ramsay RG, Cowin AJ: Collagen loss and impaired wound healing is associated with c-myb deficiency. J Pathol 2007;211:351-361.

49 Ma HH, Yao JL, Li G, Yao CL, Chen XJ, Yang SJ: Effects of c-myb antisense rna on tgf-beta1 and beta1-i collagen expression in cultured hepatic stellate cells. World J Gastroenterol 2004;10:3662-3665.

50 van den Borne SW, Diez J, Blankesteijn WM, Verjans J, Hofstra L, Narula J: Myocardial remodeling after infarction: The role of myofibroblasts. Nat Rev Cardiol 2010;7:30-37.

51 Buck M, Kim DJ, Houglum K, Hassanein T, Chojkier M: C-myb modulates transcription of the alphasmooth muscle actin gene in activated hepatic stellate cells. Am j Physiol Gastrointest Liver Physiol 2000;278:G321-328.

52 Kolodziejska KM, Noyan-Ashraf MH, Nagy A, Bacon A, Frampton J, Xin HB, Kotlikoff MI, Husain M: C-mybdependent smooth muscle cell differentiation. Circ Res 2008;102:554-561.

53 Liu W, Liu Y, Zhang Y, Zhu X, Zhang R, Guan L, Tang Q, Jiang H, Huang C, Huang H: Microrna-150 protects against pressure overload-induced cardiac hypertrophy. J Cell Biochem 2015;116:2166-76.

54 Tang Y, Wang Y, Park KM, Hu Q, Teoh JP, Broskova Z, Ranganathan P, Jayakumar C, Li J, Su H, Tang Y, Ramesh G, Kim IM: Microrna-150 protects the mouse heart from ischaemic injury by regulating cell death. Cardiovasc Res 2015;106:387-397.

55 Tardiff JC: Sarcomeric proteins and familial hypertrophic cardiomyopathy: Linking mutations in structural proteins to complex cardiovascular phenotypes. Heart Fail Rev 2005;10:237-248.

56 Debold EP, Schmitt JP, Patlak JB, Beck SE, Moore JR, Seidman JG, Seidman C, Warshaw DM: Hypertrophic and dilated cardiomyopathy mutations differentially affect the molecular force generation of mouse alphacardiac myosin in the laser trap assay. Am J Physiol Heart Circ Physiol 2007;293:H284-291. 